\title{
A Novel Approach to Develop Chalcogenide Glasses and Glass-Ceramics by Pulsed Current Electrical Sintering (PCES)
}

\author{
Gaelle Delaizir ${ }^{1}$ and Laurent Calvez ${ }^{2}$ \\ ${ }^{1}$ Groupe d'Etudes des Matériaux Hétérogènes (GEMH, ENSCI), \\ Centre Européen de la Céramique, 12 rue Atlantis, Limoges, \\ ${ }^{2}$ Equipe Verres et Céramiques, UMR CNRS Sciences Chimiques de Rennes, \\ Université de Rennes 1, Rennes Cedex, \\ France
}

\section{Introduction}

Chalcogenide glasses have been in the last decades, of paramount interest for night vision devices because of their remarkable transparency in the two atmospheric windows $(3-5 \mu \mathrm{m}$ and $8-12 \mu \mathrm{m})$. Chalcogenide glasses tend to replace, at least partially, the expensive monocrystalline Ge or polycrystalline ZnSe for infrared (IR) lenses (Zhang et al., 2003). The ease of processing due to their viscoplastic property and the lower cost of chalcogenide glasses compared to mono-crystalline Ge have made them one of the best candidates for lenses of optical thermal imaging cameras but are also very efficient for various fields of applications working in the second and third atmospheric windows. Thus, chalcogenide glasses are at the centre of active and passive applications such as night vision (Guillevic et al., 2009), generation of new infrared sources (Troles et al., 2010), electronic devices (Danto et al., 2010), chemical and biological sensors to detect $\mathrm{CO}_{2}$ or tumors respectively (Wilhelm et al., 2007), etc. They are also promising materials for energy applications, such as solid electrolyte (Hayashi et al., 2001) or thermoelectric materials (Goncalves et al., 2010). These glasses that contain no oxygen in their composition are usually synthesized in vacuumed silica ampoules using the so-called melt-quenching technique. The low thermal conductivity of silica limits the cooling rate during quenching. This usually leads to heterogeneous composition in the case of unstable glass composition (that tends to crystallize) and thus, reduces the glassy domain as well as the available diameters of these glasses. In this chapter, we describe a novel approach to synthesize chalcogenide glass bulks with large diameters including unstable compositions. This technique combines either the mechanical alloying to get amorphous powder or the grinding of glass obtained from previous small diameter melt-quenching technique and the Pulsed Current Electrical Sintering (PCES) also known as Spark Plasma Sintering (SPS) (Hubert et al., submitted). This new technique allows both the sintering of amorphous powder and its shaping in one step in few minutes. This paves the way for a new set of glasses previously impossible to synthesize, especially for crystallization concerns. Indeed, the fast heating rates reached by SPS (Joule effect heating) prevents the glass from undesirable crystallization. Also, the SPS technique is efficient to 
make IR glass-ceramics from glass powder with reduced time of crystallization in comparison with conventional technique, i.e, heating a glass bulk in a conventional furnace (Delaizir et al., 2010). Two different compositions have been tested: $62.5 \mathrm{GeS}_{2}-12.5 \mathrm{Sb}_{2} \mathrm{~S}_{3}-$ $25 \mathrm{CsCl}(\% \mathrm{~mol})$ and $80 \mathrm{GeSe}_{2}-20 \mathrm{Ga}_{2} \mathrm{Se}_{3}(\% \mathrm{~mol})$; the results are reported.

Finally, this chapter reports on an analysis of SPS consolidation of the latest chalcogenide glass composition little studied so far as well as the mechanisms of sintering and devitrification through the SPS technique.

\section{Chalcogenide glasses and glass-ceramics}

\subsection{Background}

Chalcogenide glasses are, by definition, glasses which contain at least one of the three elements: sulphur, selenium and tellurium and no oxygen. Depending on the application, other chemical elements such as arsenic, antimony, germanium, etc are added to improve mechanical and optical properties and also to increase the stability against devitrification. The most interesting property of these glasses is associated with their transparency in the mid and far infrared (IR).

Glass-ceramics are defined as polycrystalline solids prepared by the controlled crystallization of glasses with an appropriate thermal treatment. They can also be seen as composite materials made of a glassy matrix containing crystals as fillers [Mc Millan, 1979]. These kinds of materials may have exceptional properties that can be optimized according to the targeted applications. In the literature, Stookey from Corning is the first who discovered accidentally this new material, called glass-ceramics, in the middle of the 1950s. Glass-ceramics are preferred to glasses because of their better mechanical properties and are usually preferred to ceramics because of the ease of processing. Indeed, moulding is easier, faster and cheaper than solid state sintering which is the common way to produce crystalline ceramics.

\subsection{Synthesis}

\subsubsection{Glass}

\subsubsection{Melt-quenching technique}

The chemical elements constituting the glass, weighed in predetermined quantities are introduced in the set-up as shown in Fig. 1. They are put under secondary vacuum during few hours then the reactional tube is obtained by sealing the silica tube (Fig. 1).

The reactional tube is then heated in a rocking furnace at the very low rate of $2^{\circ} \mathrm{C} / \mathrm{min}$ (to avoid the rapid formation of vapor and therefore the explosion of the tube) until the homogenization temperature which depends on the glass composition. The glassy composition stays few hours at this temperature. The tube containing the melt is quenched into water or air. The glass rod is then annealed in an annealing furnace previously heated at a temperature $\mathrm{T}_{\text {annealing }}$ near the glass transition temperature $\mathrm{Tg}$ and then slowly cooled down to room temperature to release mechanical stress induced by the quenching. We therefore obtain a glass rod (Fig. 2). Usually to reach a high transmittance, raw elements 
such as sulphur or selenium are purified to avoid losses of transmission due to absorption bands (S-H, Se-H, O-H, etc)



Fig. 1. Experimental set-up.

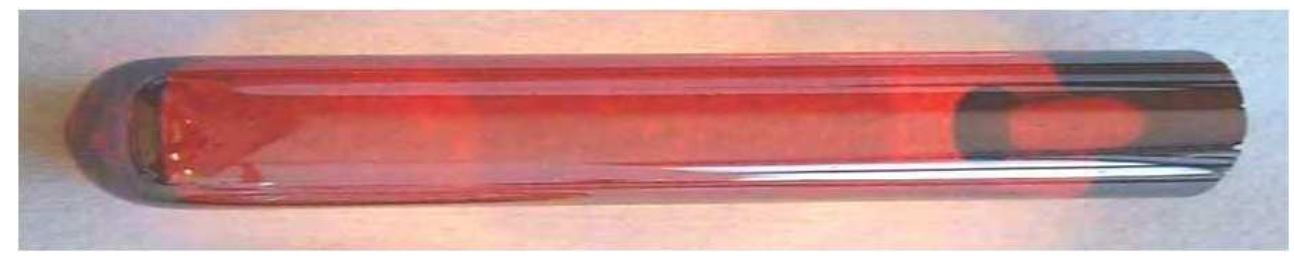

Fig. 2. Example of glass rod of the $\mathrm{GeS}_{2}-\mathrm{Sb}_{2} \mathrm{~S}_{3}-\mathrm{CsCl}$ composition.

\subsubsection{Mechanical milling}

High energy ball milling process has been demonstrated to be a promising method for the preparation of amorphous powder with fine microstructure. The amorphization reaction during mechanical milling is usually attributed to microstructural breakdown followed by the interdiffusion of elements (Johnson, 1986) or mechanically driven atomic mixing (Lund et al., 2004 \& Delogu et al., 2005) among previously formed nanocrystalline multilayers. In mechanical milling experiments, the kinetic process of the amorphization reactions usually proceeds slowly and therefore a glass forming composition is determined only after milling for an extended time (usually >100 h) (Eckert et al., 1997, Schurak et al., 1999 \& Choi et al., 2006) (Fig. 3). The ability to synthesize a dense material from amorphous powders obtained by mechanical-alloying has recently been demonstrated for many systems regarding metallic glasses (Yan et al., 2008, Patil et al., 2005 \& Kim et al., 2005). Also, amorphous powders in the systems $\mathrm{Li}_{2} \mathrm{~S}-\mathrm{P}_{2} \mathrm{~S}_{5}$ or $\mathrm{AgI}-\mathrm{As}_{2} \mathrm{Se}_{3}$ have been synthesized using the same method for solid electrolyte applications (Hayashi et al., 2001, Sekine et al., 2007 \& Trevey et al., 2009). Few papers report the amorphization of metallic elements used in the manufacture of IR glasses; they are limited to the study of Ge-Se powder but none of these papers are relevant for the production of optical devices (Shirakawa et al., 2001 \& Machado et al., 2005). 


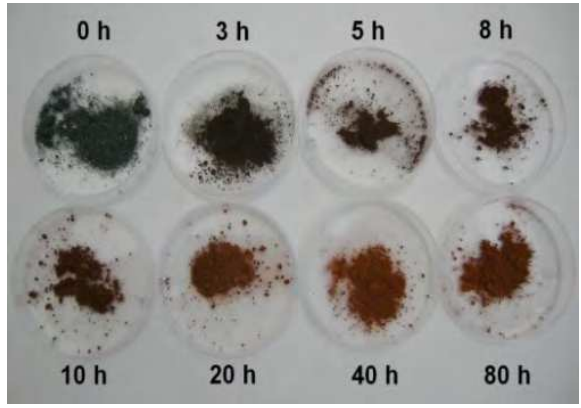

(a)

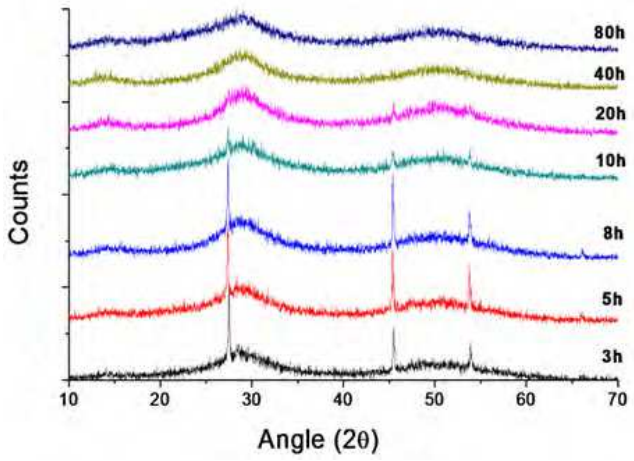

(b)

Fig. 3. (a) Evolution of the $80 \mathrm{GeSe}_{2}-20 \mathrm{Ga}_{2} \mathrm{Se}_{3}$ powder color with the milling duration (b) XRD patterns of the corresponding powders obtained at different milling durations showing the progressive amorphization of the powder.

\subsubsection{Glass-ceramics}

Glass-ceramics synthesis, or the devitrification process of the glassy matrix, implies a twostep procedure: nucleation and crystal growth.

Nucleation represents the first step of glass devitrification. It consists in inducing germinate from which the growth can start. It is based on kinetic parameters. Nucleation may be homogeneous or heterogeneous. In homogeneous nucleation, the first tiny seeds are of the same constitution as the crystals which grow upon them, whereas, in the case of heterogeneous nucleation, the nuclei can be quite different chemically from the crystals which are deposited. Some substances enabling or hastening bulk nucleation can be added to glass composition; they are termed nucleating agent. We can distinguish two types of nucleating agents. Metallic nucleating agent such as $\mathrm{Au}, \mathrm{Cu}, \mathrm{Pt}$, etc, are added to the glass in very small amounts (0.01 to $1 \%$ mass). The mechanisms of the effect of these nucleation agents in increasing the nucleation rate of the principal crystalline phase is quite complex but is based on heterogeneous nucleation. A second group of nucleating agents including $\mathrm{TiO}_{2}, \mathrm{ZrO}_{2}, \mathrm{SnO}_{2}, \mathrm{P}_{2} \mathrm{O}_{5}$ (in the case of oxide glass-ceramics) or metallic sulphide can be added in greater amounts (mostly up to $20 \%$ ) in order to get oxide glass-ceramics. They are part of the oxide glassy composition and they are found to be effective nucleating agents in specific initiation of bulk nucleation.

The so called TTT curve (Time, Transformation rate, Temperature) can predict the time needed to crystallize a fraction of glass at one given temperature. The advantage of the TTT curve (Fig. 4a) lies in the fact that it permits the determination of a critical point for which the time needed for crystallization is minimal and the temperature for instability is maximal. Avrami's equation permits to build TTT curve (Avrami, 1939).

$$
x=1-e^{-f} \text { with } f=(k t)^{n}
$$

Where $\mathrm{n}$ is the Avrami exponent. This equation is valid if the nucleation is monotonous.

It is assumed that $\mathrm{k}$, the rate constant, varies with time according to the Arrhenius law: 


$$
k=k_{0} \times \exp \left(\frac{-E}{R T}\right)
$$

where $\mathrm{E}$ is the activation energy and $\mathrm{k}_{0}$, a frequency factor.

Without nucleation, crystal growth cannot happen and without growth, no crystals can appear. These processes must take place within a certain range of temperatures which is critical for the devitrification (Fig. 4b). Above the melting temperature, Tm, the liquid constitutes the stable phase. When the liquid cools down, the crystal growth can theoretically happen between T2 and T4. However, the initial nuclei needed before the crystal growth can theoretically happen between $\mathrm{T} 1$ and $\mathrm{T} 2$. The critical range is therefore between T2 and T3 (in the case of non addition of nucleating agents in the glass).

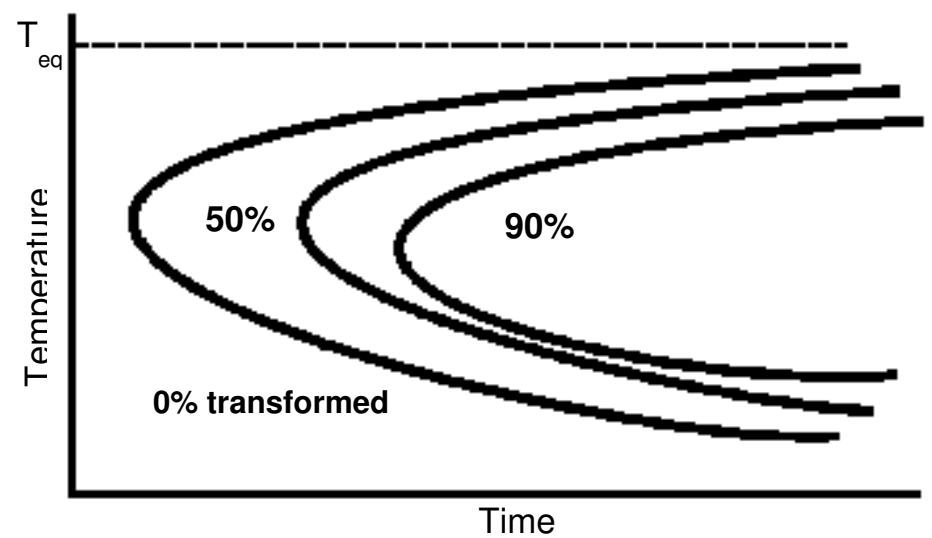

(a)

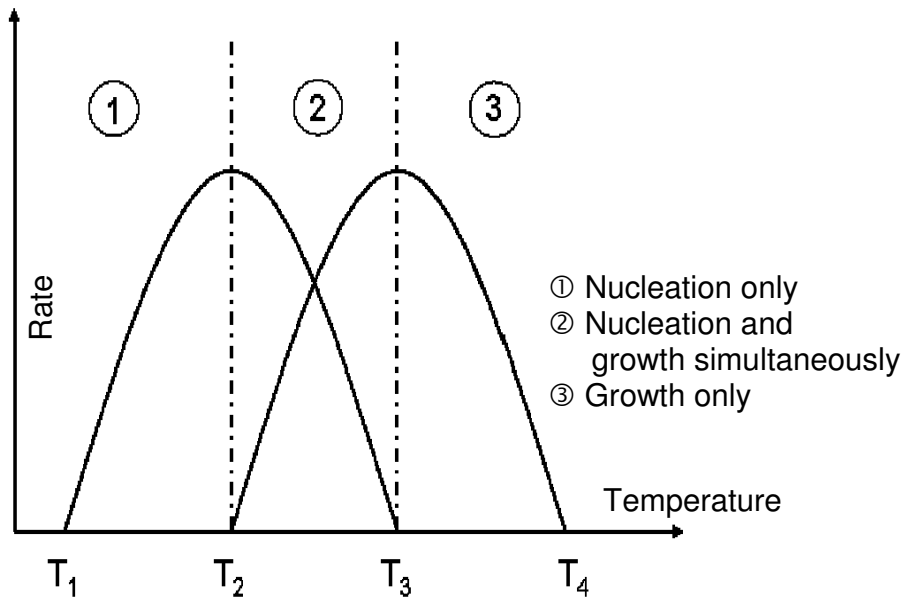

(b)

Fig. 4. (a) Example of TTT curve, (b) Nucleation and growth phenomena as a function of temperature. 
The common treatment to obtain glass-ceramics is an appropriate thermal treatment from a base glass. The thermal treatment used in industry to get this material is a "two plateaus" treatment. It consists of heating the glassy matrix (base glass) at a temperature above the glass transition temperature, $\mathrm{Tg}$ in order to induce nuclei in the glass. The temperature is then increased to a second plateau to induce the growth of these nuclei. A second technique consists in a single plateau. The glass is heated at a temperature above $\mathrm{Tg}$ but below the crystallization temperature, Tc. This technique allows the nucleation phenomenon and avoids excessive growth.

Oxide glass-ceramics are by far the most studied glass-ceramics. They have been widely investigated since 1950 and the research associated to this area is now slowing down. Today, research is more focused on the nucleation and growth phenomena to have a better understanding. However chalcogenide glass-ceramics still remain of great interest because of their transparency in the infrared range associated to better mechanical properties. As previously mentioned, potential applications are infrared lenses for thermal camera.

Chalcogenide glass-ceramics transparent in the range 8-12 $\mu \mathrm{m}$ were first synthesized in 1973 by Mecholsky in the system $0.3 \mathrm{PbSe}-0.7 \mathrm{Ge}_{1.5} \mathrm{As}_{0.5} \mathrm{Se}_{3}$ with a $60 \%$ crystalline fraction. He showed that the glass-ceramic modulus of rupture was increased to as much as twice that of the base glass and the Vickers hardness increased by 30\% (Mecholsky et al., 1976).

Other researchers worked on systems such as As-Ge-Se-Sn (Cheng, 1982), Ga-Ge-Sb-Se (Ma et al., 2003) or Ge-Te-Se (Song et al., 1997) but the reproducibility of the glass-ceramics synthesis remained difficult.

First chalco-halide glass-ceramics, transparent in the far infrared $(10 \mu \mathrm{m})$ was obtained in 2003 within the system $\mathrm{GeS}_{2}-\mathrm{Sb}_{2} \mathrm{~S}_{3}-\mathrm{CsCl}$ in the "Glass and Ceramic" laboratory in Rennes (France) (Zhang et al., 2004) (Fig. 5). The simultaneous presence of ionic and covalent compounds prevent from the rapid and uncontrollable crystallization. Three years later, glass-ceramics transparent until $14 \mu \mathrm{m}$, covering the second and third atmospheric windows entirely, were synthesized in the system $\mathrm{GeS}_{2}-\mathrm{Ga}_{2} \mathrm{Se}_{3}-\mathrm{CsCl}$ (Calvez et al., 2007).

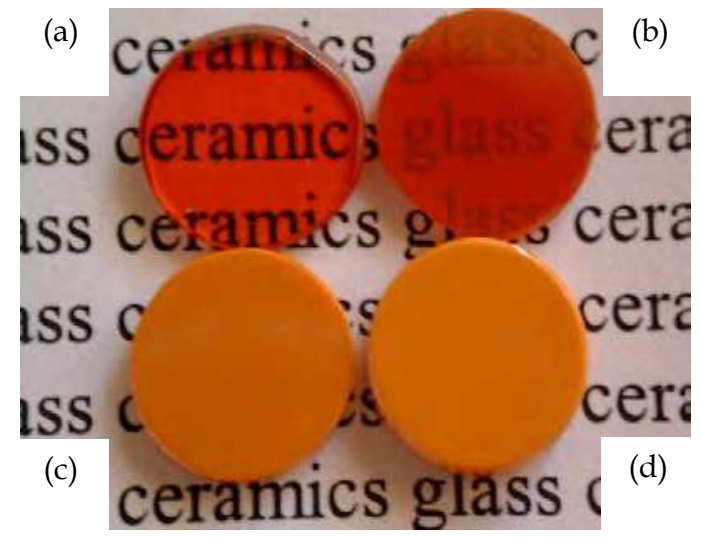

Fig. 5. Glass composition $62.5 \mathrm{GeS}_{2}-12.5 \mathrm{Sb}_{2} \mathrm{~S}_{3}-25 \mathrm{CsCl}$ heated at $290^{\circ} \mathrm{C}$ for different crystallization times (a) No thermal treatment (b) $7 \mathrm{~h} \mathrm{(c)} 73 \mathrm{~h}$ and (d) $144 \mathrm{~h}$. 


\subsection{Physical properties}

\subsubsection{Thermal properties}

Thermal characteristics of a glass, such as glass transition temperature Tg and crystallization temperature Tc, are determined using Differential Scanning Calorimetry (DSC). Fig. 6 represents the thermogram heat flow versus temperature for one given glass undergoing crystallization phenomenon (exothermic peak). Glasses which are stable against devitrification do not present any crystallization peak.

The glass transition temperature, $\mathrm{Tg}$, is the main characteristic of a glass. Before $\mathrm{Tg}$, the viscosity is infinite (solid state), at $\mathrm{Tg}$, the viscosity is equal to $10^{13}$ poises (1012 $\mathrm{Pa} . \mathrm{s}$ ) and after $\mathrm{Tg}$, the viscosity decreases as the temperature increases, therefore, the material can be easily shaped. The crystallization phenomenon is characterized by the rearrangement of atoms in organized lattice due to the change of viscosity. Crystallization is at the origin of the loss of the viscoplastic properties as well as the optical transparency. The stability against devitrification is associated with the difference Tc-Tg. The higher is the difference between $\mathrm{Tc}$ and $\mathrm{Tg}$ and better is the stability against devitrification.

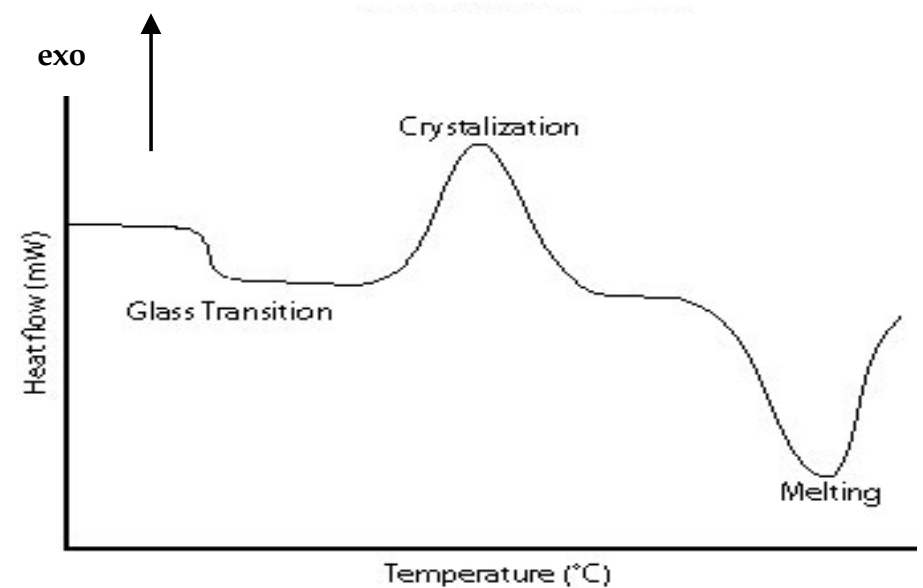

Fig. 6. Typical DSC curve for a glass.

\subsubsection{Optical properties}

Optical transmission of glasses is characterized by its optical window. At shorter wavelengths, the band gap limits the optical window while at longer wavelengths the optical window is limited by the multi-phonon absorption.

The band gap results from electronic transition inside the glass. Photons with sufficient energy are absorbed by exciting electrons across the forbidden band-gap. The electrons are excited from the top of the valence band to the bottom of the conduction band. In glasses, additional states exist just above the valence band and just below the conduction band. These states are present because the disorder creates localized electronic states. These localized states participate in the absorption process. 
In chalcogenide glasses, absorption phenomena are due to the excitation of non bonding electrons of chalcogenide chemical element: S, Se or Te. Because non bonding electrons of selenium $\left(4 s^{2} p^{4}\right)$ or tellurium $\left(5 s^{2} p^{4}\right)$ are higher in energy than bonding electrons of sulphur $\left(3 s^{2} p^{4}\right)$, they are more excitable. Therefore, the band gap shifts from visible with sulphurbased glass to near infrared for selenium or tellurium-based glass.

The multi-phonon absorption at longer wavelengths deals with interaction between light and vibration modes of the chemical bonds inside the glass. The phonon energy, E, is directly linked to the atoms weight and is inversely proportional (Kittel, 1998). The large atomic mass of chalcogenide elements causes the phonon vibrations to have low energies. Materials with high phonon energies have multi-phonon absorption in the mid- and nearinfrared region. This is especially true for materials with lightweight, strongly bounded atoms such as silica glasses and it limits their usefulness for infrared applications. Chalcogenide glasses typically have optical windows that extend into the far infrared beyond $12 \mu \mathrm{m}$ (Klocek et al., 1987).

The transmission spectra (Fig. 7) illustrate the multi-phonon absorption for different types of glass (oxide, fluoride and chalcogenide glasses with $\mathrm{S}$, Se and Te). The molecular weight $(\mathrm{MW})$ is in the order: $\mathrm{MW}(\mathrm{O})<\mathrm{MW}(\mathrm{F})<\mathrm{MW}(\mathrm{S})<\mathrm{MW}(\mathrm{Se})<\mathrm{MW}(\mathrm{Te})$, therefore the multiphonon absorption for chalcogenide glasses is shifted toward longer wavelengths compared to oxide or fluoride based-glass compositions.

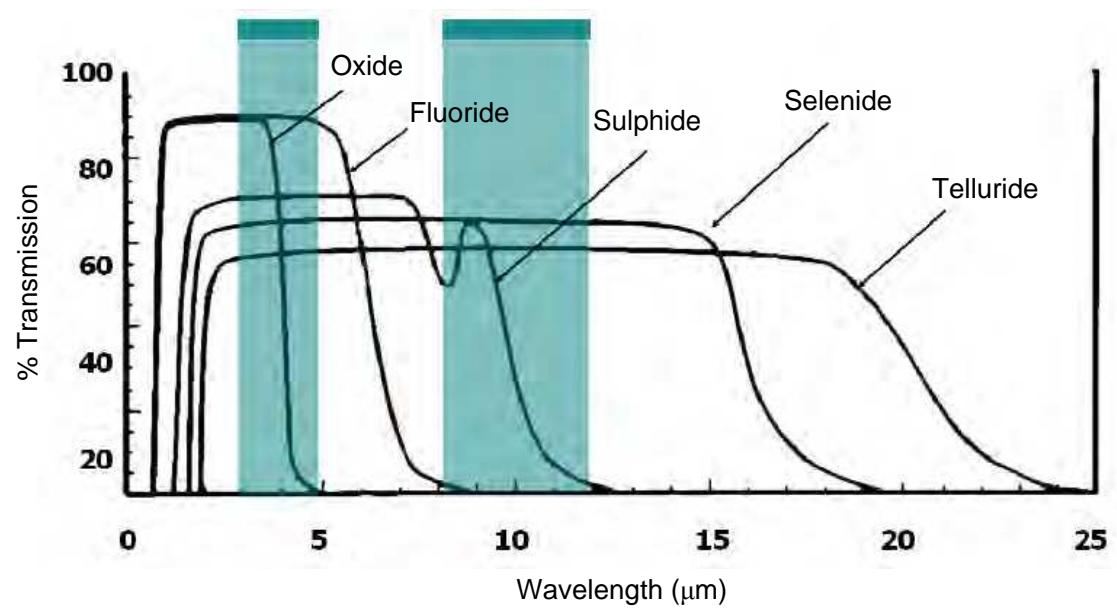

Fig. 7. Optical window of different types of glass.

\subsubsection{Other properties}

General observation regarding glass-ceramics compared to the derivative base glass shows an increase of toughness, stiffness and hardness as well as an interruption of the crack propagation due to crystals (Choi et al., 2003) (Fig. 8). Mechanical properties of glassceramics are influenced by several factors such as particle size and volume fraction of crystalline phase (which can be up to $90 \%$ ), interfacial bond strength, differences in elastic modulus and thermal expansion between the glassy matrix and the crystals, etc. 


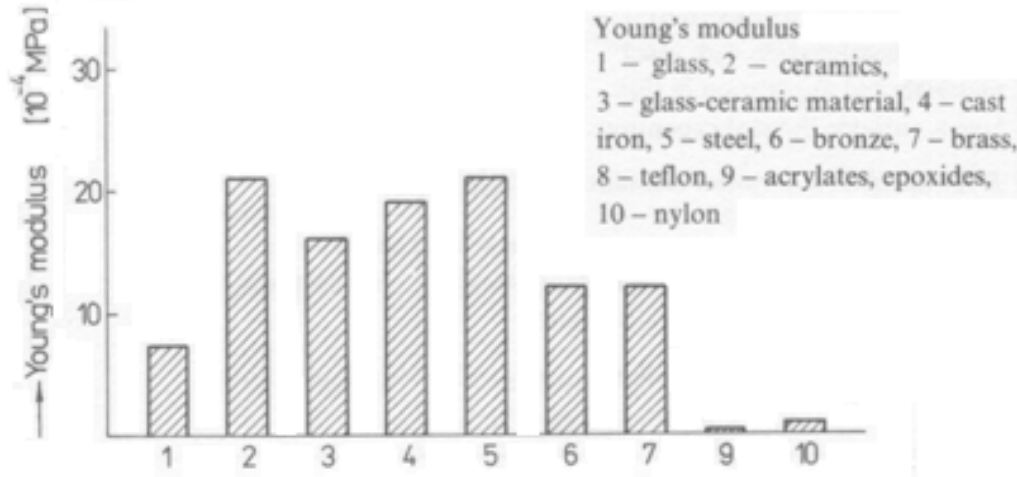

Fig. 8. Young's modulus for different materials (Strnad, 1986).

The increase of mechanical properties is maybe the most important advantage of glassceramics over glasses but glass-ceramics present other great advantages. Because of their adjustable coefficient of thermal expansion, glass-ceramics are resistant to thermal shock and permit the sealing to a variety of metals (mostly for oxide glass-ceramics). Then depending on the crystal size, glass-ceramics can be totally transparent or opaque. Oxide glass-ceramics are also used in electronic for their wide range of dielectric constants and are chosen instead of glasses for their lower dielectric losses. They are also corrosion resistant against weathering and a wide range of chemicals.

Electrical properties of chalcogenide glasses depend on their chemical composition. They can be seen as semiconductors because they possess a band gap energy $(\sim 2 \mathrm{eV})$ characteristic of semiconductor materials $(1-3 \mathrm{eV})$. This band-gap $\left(\mathrm{E}_{\mathrm{g}}\right)$ depends on the glass composition and is smaller for tellurium based-glass composition $\left(\mathrm{E}_{\mathrm{g}}(\mathrm{S})>\mathrm{E}_{\mathrm{g}}(\mathrm{Se})>\mathrm{E}_{\mathrm{g}}(\mathrm{Te})\right)$ (Table 1). The electrical conductivity of semi-conductors at room temperature is in the range $10^{2}-10^{-9} \Omega^{-1} \cdot \mathrm{cm}^{-1}$ (Kittel, 1998). The electrical conductivities of sulfur and selenium basedglass compositions are very low. They can therefore be seen as insulator in contrary to telluride based-glass composition.

\begin{tabular}{|c|c|c|}
\hline & $\mathrm{Eg}(\mathrm{eV})$ & $\sigma(\Omega-1 . \mathrm{cm}-1)$ \\
\hline As2S3 & 2.12 & $10-17$ \\
\hline As2Se3 & 1.53 & $10-12$ \\
\hline As2Te3 & 0.3 & $10-4$ \\
\hline
\end{tabular}

Table 1. Comparison of band-gap and electrical conductivity of sulphide, selenide and telluride based-glass composition (Elliott, 1991).

\section{The Pulsed Current Electrical Sintering (PCES) technique}

\subsection{Outline}

The Pulsed Current Electrical Sintering (PCES) also known as Spark Plasma Sintering (SPS), Field Assisted Sintering Technique (FAST) or Electric Current Activated Sintering (ECAS) is a powerful technique for powder consolidation. This technology started in the late 1920s 
when a sintering process using electrical energizing was introduced in the USA. In the meantime, in Japan, an ongoing research on the process of pulsed current activated sintering intensified and was patented in the 1960s [Inoue, 1962 \& Inoue, 1966). This method seems to be characterized by technical and economical advantages over conventional sintering methods such as Hot Uniaxial Pressing (HUP), Hot Isostatic Pressing (HIP), etc. Indeed, the fast heating rate, the short holding times, the absence of sintering aids, the lower sintering temperatures, the improved properties of the process ceramic in comparison with other sintering methods, no need of cold compaction make the PCES a very competitive technique for industrial applications and for the field of materials research. As a proof, the number of research papers is exponential since the late 1990s when research lab worldwide started to be equipped with this technology [Orru et al., 2009]. Moreover, with the fast heating rates and short holding times, the processing of nano-powders was then possible to keep the nanostructure of the ceramics.

\subsection{Process description}

The description of the process is illustrated in Fig. 9. DC pulses allow the conducting die (graphite, WC, stainless steel) to heat by Joule effect while a uniaxial load can be applied. The PCES can therefore be seen as similar as Hot Uniaxial Pressing (HUP) technique with faster heating rate up to $1000^{\circ} \mathrm{C} / \mathrm{min}$. However, specific experimental sets-up have been designed in order to apply isostatic (Saito \& Sawaoka, 1973) or quasi-isostatic (Song et al., 2004) pressure to the sample to be consolidated. The sintered powder can be either conductive or insulating. Depending on the electrical properties of the powder, the heating mechanisms are different (Anselmi-Tamburini et al., 2005). In the case of insulating powder, the heating mostly occurs through the container (die) while conducting powders are heated by Joule effect and by heat transfer from the container and electrodes. If the powder is conductive, an insulating die can be used. The mechanical load applied depends on the nature of the container. The load is usually limited to $120 \mathrm{MPa}$ in the case of graphite die but can be much more in the case of WC die $(800 \mathrm{MPa})$. However, graphite die can be heated up to $2000^{\circ} \mathrm{C}$ while WC can be heated up to $900^{\circ} \mathrm{C}$ depending on the applied load. Different working atmosphere can be applied during experiments: vacuum, neutral, reducing, etc.

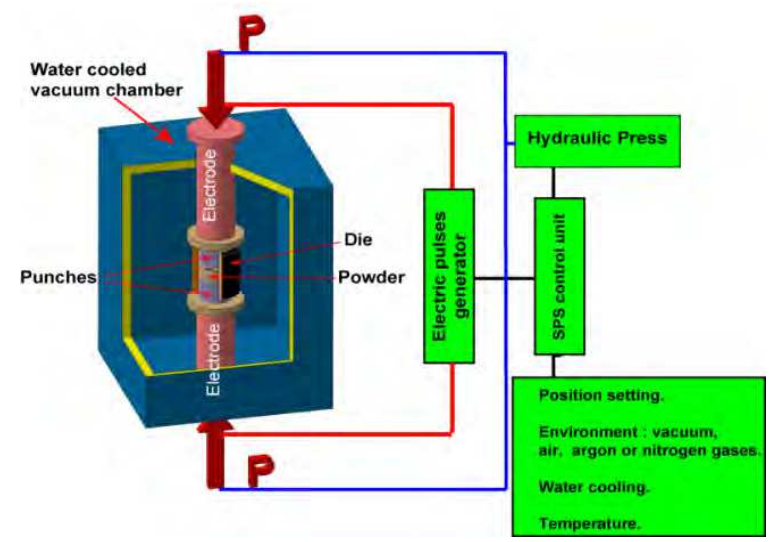

Fig. 9. Process description of PCES technique (Hungria et al., 2009). 
This technique is also very interesting as it permits to sinter and shape in a single step a wide range of materials into conventional (cylinder, etc) and non conventional shapes (ball, etc) (Hungria et al., 2009). The diameter, depending on the machine and the sintering conditions, can range from $8 \mathrm{~mm}$ to $100 \mathrm{~mm}$ or up. It should be however mentioned that in PCES processes the problem of adequate electrical conductance of the powders and the achievement of homogenous temperature distribution is particularly acute, especially for large diameter samples. In fact, current and consequent temperature distributions within the sample are very sensitive to the homogeneity of density distribution. Moreover, large density spatial variation, especially at the beginning of current flow, may result in high local overheating or even melting (Orru et al., 2009). That is why, some researchers focused now on modeling the thermal gradient during experiment. Then, some graphite pollution can occur during SPS experiment that is detrimental for optical applications for example (Bernard-Granger et al., 2009). This can be solved by using inner tantalum (Ta) foil or boron nitride $(\mathrm{BN})$ layer as graphite barrier diffusion.

\subsection{State of the art of the materials investigated}

A large number of sintered materials have been tested until now among which we can cite: metals and alloys, intermetallics, carbides, borides, nitrides, silicides, oxides, sialon, ceramic-metal and ceramic-intermetallic composites, ceramic-ceramic composites, hydroxyapatite-based materials, chalcogenides, polymer-based materials, functional graded materials, systems for joining, graphite/carbon-based materials including composites containing carbon-nanotubes, multi-materials including solid state batteries (Aboulaich et al., 2011) and other systems. A review of the materials tested can be found elsewhere Orru et al., 2009). The highlights are that higher densities can be achieved at lower sintering temperature in shorter sintering time and that smaller grain sizes ceramics are typically obtained with a consequent direct effect on nearly all properties investigated on the fabricated dense materials.

In the literature, the sintering of glasses by SPS mostly concerns conductor metallic glasses (Li et al., 2009; Shin et al., 2010 \& Choi et al. 2007). These glasses which composition can include several chemical elements among $\mathrm{Zr}, \mathrm{Ti}, \mathrm{Al}, \mathrm{Cu}, \mathrm{Pd}, \mathrm{Mg}, \mathrm{Pt}, \mathrm{Ca}, \mathrm{Fe}, \mathrm{Ni}, \mathrm{Co}$ and sometimes rare earth are largely studied for their good mechanical properties. In this case, the SPS technique is very interesting since the heating rates are fast enough to avoid the crystallization phenomenon of these unstable glasses. These amorphous materials are most often obtained by mechanical alloying, melt-spinning or atomization. Recently, Nowak et al. (Nowak et al., 2011) and Perriere et al. (Perriere et al., 2011) studied the phenomenon during SPS treatment at the origin of the microstructure and densification of glasses. The devitrification in metallic glasses during SPS treatment has also been studied in order to obtain composite materials or glass-ceramics (Li et al., 2010). Except this study on metallic glasses, we can cite the research activity of Mayerhofer et al. on the sintering of amorphous silica nano-particles by SPS (Mayerhofer et al., 2008). The sintering of chalcogenide glasses and the in situ synthesis of glass-ceramics by SPS has been little studied to the best of our knowledge. We can identify a study on oxide glasses from the $\mathrm{SiO}_{2}-\mathrm{Al}_{2} \mathrm{O}_{3}-\mathrm{Li}_{2} \mathrm{O}: \mathrm{Er}^{3+}$ system (Riello et al., 2006) and the ones we propose in this chapter on the $\mathrm{GeS}_{2}-\mathrm{Sb}_{2} \mathrm{~S}_{3}-\mathrm{CsCl}$ and $\mathrm{GeSe}_{2}-\mathrm{Ga}_{2} \mathrm{Se}_{3}$ glassy systems (Hubert et al., submitted \& Delaizir et al., 2010). These last studies clearly show the advantage of SPS for the shaping of glass and the gain of time 
concerning the synthesis of glass-ceramics in comparison with a conventional technique in a conventional furnace.

Recent results also suggest that the Spark Plasma Sintering is a new technique to achieve very fast solid state chemistry (Galy et al., 2008). This technique appears as a new synthesis technique which permits to decrease both the temperature and time reaction while mastering the particle size. Even though all the mechanisms are not well understood, it is generally agreed that an accelerated diffusion process due to the electrical discharge is at the origin of the fast reactivity by SPS (Galy et al., 2008).

The SPS or PCES still remains controversial with plasma formation or not, removal of oxides (breakdown of oxides films) and adsorbed gases from the particle surfaces with a resulting cleaning effect, high localized temperature at the contact area between particles, enhanced diffusion of materials at forming particle necks (Orru et al., 2009) since no evidence has been proven. Thermal gradients are also very discussed especially for large diameters. However research on SPS mechanisms to answer to these questions as well as modeling is of growing and fundamental interests.

\section{The Pulsed Current Electrical Sintering (PCES) technique applied to the preparation of chalcogenide glasses and glass-ceramics}

\subsection{Principle}

As previously mentioned, the common way to prepare chalcogenide glasses is the meltquenching technique in silica tube under vacuum. Due to the low thermal conductivity of silica during quenching, this leads to heterogeneous glass sample when the composition is unstable $\left(\mathrm{Tc}-\mathrm{Tg}<100^{\circ} \mathrm{C}\right)$. Usually the inner part of the glass is crystallized and the outer part amorphous. Therefore, this limits the preparation of glass samples to small diameters to ensure homogeneity of the glass. Glass-ceramics are obtained by heating a glass bulk with an appropriate thermal treatment in a furnace. According to targeted crystal fraction and crystals size, this can take up to hundreds of hours. It is well known that grained glass samples devitrify more easily than glass bulk samples and upon a process of amorphous state sintering and simultaneous or subsequent crystallization, glass-ceramic materials can be obtained (Gutzow et al., 1998).

Grained glass samples can be either obtained by mechanical milling or by grinding and sieving pre-existing glass bulk synthesized by the conventional melt-quenching technique.

The phenomenon at the origin of easier devitrification is mostly due to pre-existing structural defects and new surfaces that act as nucleation sites in powders obtained from mechanical milling process or grinding. Therefore, it should be possible to change the kinetic process in comparison with devitrification of common glass bulks.

Moreover, the SPS or PCES technique has fast heating rates that prevent the glass powder from uncontrollable ceramization. By combining glass powder obtained from mechanical milling or grinding of pre-existing glass bulk and SPS technique, the idea is to develop an easy way to produce glass/glass-ceramics bulks with large diameters even for unstable compositions that are of great interest for optics. 


\subsection{Glasses of investigation and results}

So far two compositions have been tested: $62.5 \mathrm{GeS}_{2}-12.5 \mathrm{Sb}_{2} \mathrm{~S}_{3}-25 \mathrm{Cscl}$ and $80 \mathrm{GeSe}_{2}-20 \mathrm{Ga}_{2} \mathrm{Se}_{3}$ (mol \%). However this technique is believed to be suitable for all glass compositions to get amorphous bulks as well as glass-ceramics. These compositions were chosen for their potential applications (Huber et al., submitted \& Delaizir et al., 2010).

The glass composition $62.5 \mathrm{GeS}_{2}-12.5 \mathrm{Sb}_{2} \mathrm{~S}_{3}-25 \mathrm{Cscl}$ has been obtained through a melt-quenching technique and the resulting bulk has been grinded and sieved $(45 \mu \mathrm{m})$ while the glass composition $80 \mathrm{GeSe}_{2}-20 \mathrm{Ga}_{2} \mathrm{Se}_{3}$ has been obtained through an $80 \mathrm{~h}$ mechanical milling process from high purity metallic elements $\mathrm{Ge}, \mathrm{Ga}$ and Se (Fig. 3a). The size distribution, measured using laser diffusion technique shows low mean particle size (D50 $=3.72 \mu \mathrm{m})$. The thermal properties of these glasses are summarized in Table 2 . Tc $c_{1}$ corresponds to the crystallization of $\mathrm{CsCl}$ and $\mathrm{GeGa}_{4} \mathrm{Se}_{8}$ (or $\mathrm{Ga}_{2} \mathrm{Se}_{3}$ ) species respectively for the $62.5 \mathrm{GeS}_{2}-12.5 \mathrm{Sb}_{2} \mathrm{~S}_{3}-25 \mathrm{Cscl}$ and $80 \mathrm{GeSe}_{2}-20 \mathrm{Ga}_{2} \mathrm{Se}_{3}$ compositions. $\mathrm{Tc}_{2}$ corresponds to the crystallization of $\mathrm{GeSe}_{2}$.

\begin{tabular}{|l|l|l|l|}
\cline { 2 - 4 } \multicolumn{1}{c|}{} & $\mathrm{Tg}\left({ }^{\circ} \mathrm{C}\right)$ & $\mathrm{Tc}_{1}\left({ }^{\circ} \mathrm{C}\right)$ & $\mathrm{Tc}_{2}\left({ }^{\circ} \mathrm{C}\right)$ \\
\hline $62.5 \mathrm{GeS}_{2}-12.5 \mathrm{Sb}_{2} \mathrm{~S}_{3}-25 \mathrm{Cscl}$ & 260 & 380 & - \\
\hline $80 \mathrm{GeSe}_{2}-20 \mathrm{Ga}_{2} \mathrm{Se}_{3}$ & 347 & 449 & 470 \\
\hline
\end{tabular}

Table 2. Thermal properties of two chalcogenide glasses.

The powders were then inserted into a graphite die $(\varnothing 8,20$ or $35 \mathrm{~mm})$ with inner tantalum foil to prevent the glass from carbon contamination (Fig. 10). It is noteworthy that the glass powder is yellow due to the presence of sulphur in the composition. The corresponding sintered glass is red since the optical band gap is in the $600-700 \mathrm{~nm}$ region. According to the glass composition, different SPS parameters were tested. The typical load ranges from 50 to $100 \mathrm{MPa}$ and the optimized sintering temperatures were found to be respectively $290^{\circ} \mathrm{C}$ and $390^{\circ} \mathrm{C}$ for the $62.5 \mathrm{GeS}_{2}-12.5 \mathrm{Sb}_{2} \mathrm{~S}_{3}-25 \mathrm{Cscl}$ and $80 \mathrm{GeSe}_{2}-20 \mathrm{Ga}_{2} \mathrm{Se}_{3}$ glass compositions. The dwell times at the sintering temperature range from 2 minutes to get amorphous bulk to 90 minutes to get glass-ceramics as shown by XRD patterns (Fig. 11).



Fig. 10. Photograph of the processed glass sample for the composition $62.5 \mathrm{GeS}_{2}-12.5 \mathrm{Sb}_{2} \mathrm{~S}_{3}-$ 25Cscl. 


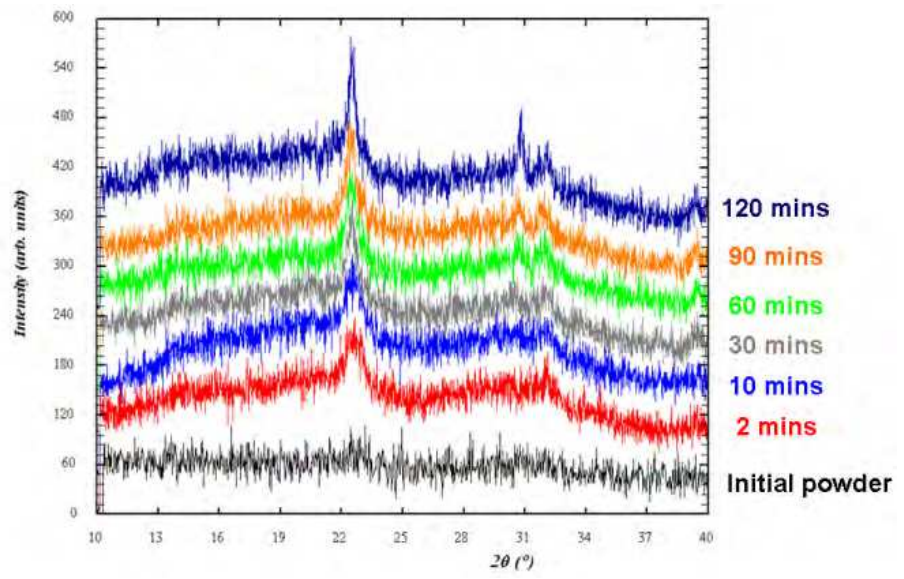

(a)

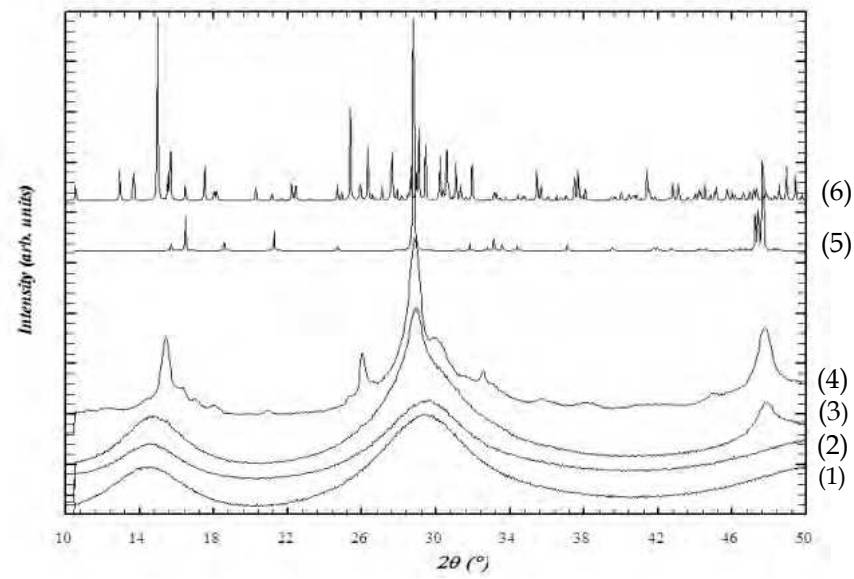

(b)

Fig. 11. X-ray diffraction patterns of (a) glass-ceramics obtained from the 62.5 $\mathrm{GeS}_{2}-12.5 \mathrm{Sb}_{2} \mathrm{~S}_{3}-25 \mathrm{CsCl}$-based glass powder for different SPS treatment times at $290^{\circ} \mathrm{C}$ under $100 \mathrm{MPa}$, (b) glass-ceramics obtained from the $80 \mathrm{GeSe}_{2}-20 \mathrm{Ga}_{2} \mathrm{Se}_{3}$ glass powder for different SPS treatment times at $390^{\circ} \mathrm{C}$ under $50 \mathrm{MPa},(1)$ initial $80 \mathrm{GeSe}_{2}-20 \mathrm{Ga}_{2} \mathrm{Se}_{3}$ powder, (2) 2'SPS treatment time, (3) 30' SPS treatment time, (4) 60' SPS treatment time, (5) crystalline $\mathrm{Ga}_{2} \mathrm{Se}_{3},(6)$ crystalline $\mathrm{GeSe}_{2}$.

The transmission of the processed glassy samples whatever their dimensions is good in the mid infrared range as observable in the picture taken by a thermal camera working in the third atmospheric window from 8 to $12 \mu \mathrm{m}$ (Figs. 12a and 12b). The absorption observed in this picture is firstly due to reflection on both faces because of the high refractive index of the $80 \mathrm{GeSe}_{2}-20 \mathrm{Ga}_{2} \mathrm{Se}_{3}$ glass composition ( $\left.\mathrm{n} \sim 2.41\right)$. Secondly, the presence of oxygen leading to the formation of $\mathrm{Ge}-\mathrm{O}$ bonds inside the bulk glass induces phonon absorption and finally 
a slight diffusion of $C$ graphite (papyex) or tantalum used as inner part of the die can also interfere (Fig. 12c). These all parameters can be improved by working under controlled atmosphere from the beginning to the end of the experiments and by pre-compacting the powder at room temperature. The sintering of large diameter is challenging in SPS experiment due to thermal gradient between the center and the periphery of the pellet. A micro-diffraction experiment has been carried out to investigate the amorphous character of the glass bulk along the diameter. Results show that no crystallization peaks are observed in the $36 \mathrm{~mm}$ diameter glass and the glass is still amorphous (Fig. 12d). For recall, this glass composition doesn't exceed a diameter of $9 \mathrm{~mm}$ using the conventional way of synthesis of chalcogenide glasses.

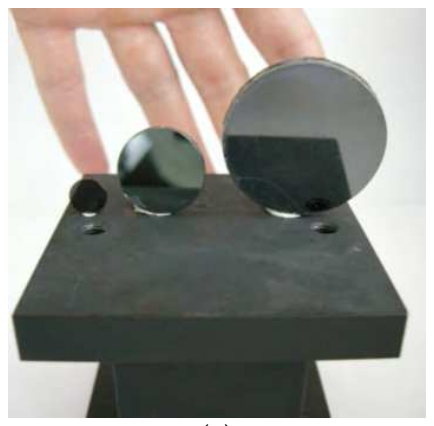

(a)

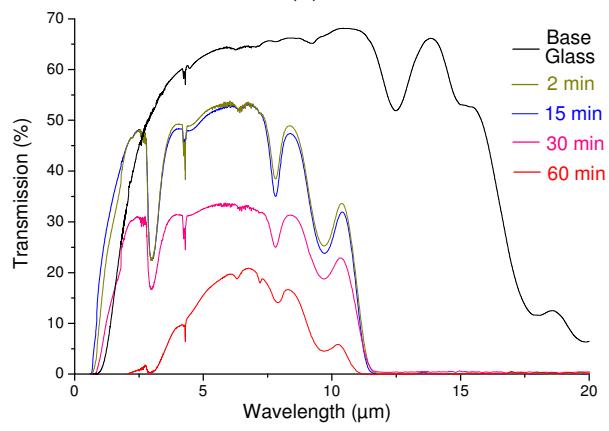

(c)

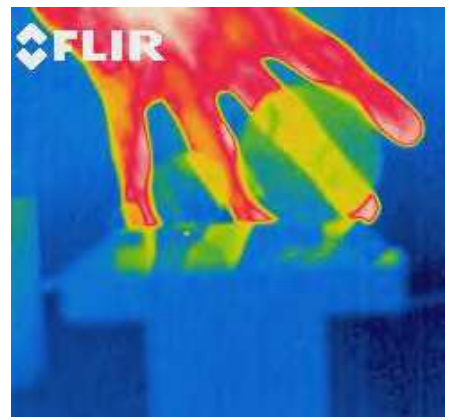

(b)

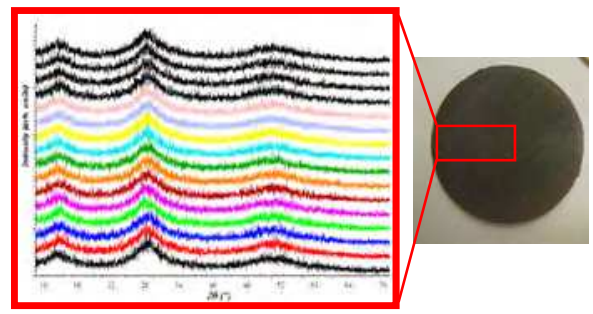

(d)

Fig. 12. (a) Photograph of the SPS processed $80 \mathrm{GeSe}_{2}-20 \mathrm{Ga}_{2} \mathrm{Se}_{3}$ glasses $(9,20,36 \mathrm{~mm}$ diameter), (b) IR picture of the corresponding glasses observed with a $8-12 \mu \mathrm{m}$ thermal camera, (c) IR spectra of the base glass synthesized in sealed silica tube, finely grinded and sintered by SPS $\left(390^{\circ} \mathrm{C}, 50 \mathrm{MPa}, 2^{\prime}\right)$, glass and glass-ceramics made by mechanical milling and SPS at $390^{\circ} \mathrm{C}$ for 2, 15, 30 and 60 min under $50 \mathrm{MPa}$, (d) X-Ray micro-diffraction patterns of the $36 \mathrm{~mm}$ diameter sample from the center to the periphery.

Similar results are obtained with the $62.5 \mathrm{GeS}_{2}-12.5 \mathrm{Sb}_{2} \mathrm{~S}_{3}-25 \mathrm{Cscl}$ glass composition that has been grinded from a bulk obtained by melt-quenching and sieved (Fig. 13). It is noteworthy that better optical transmissions are obtained with this technique in comparison with the sintering of powder obtained by mechanical milling. This supposes that some oxidation may occur during the long time mechanical milling process leading to lower optical properties. 

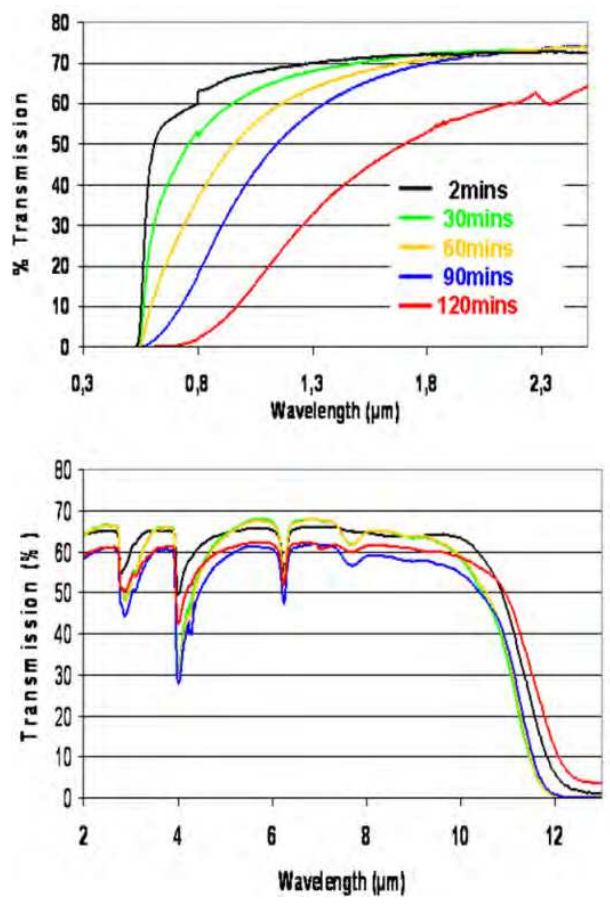

(a)

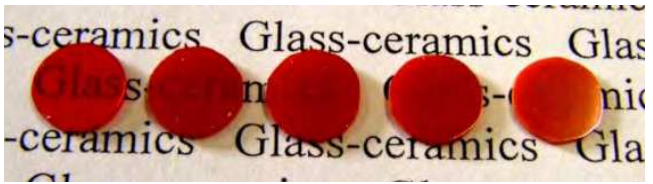

(b)
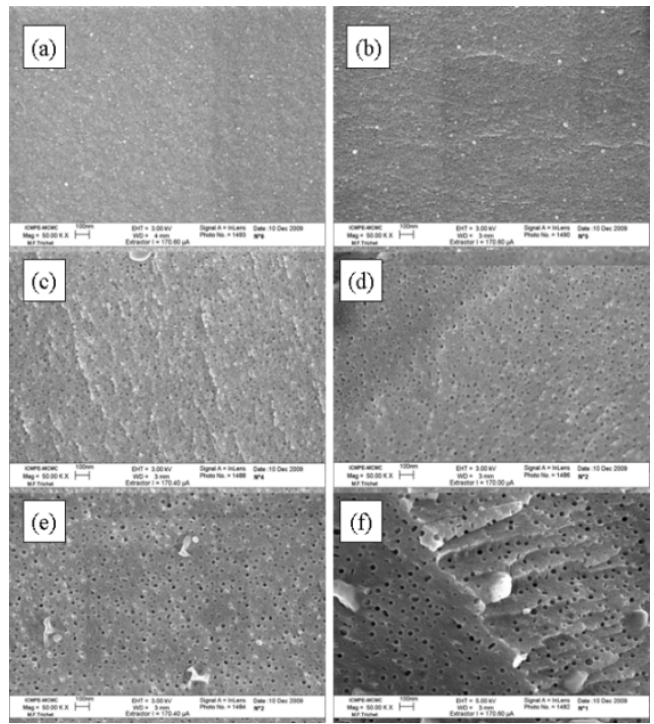

(c)

Fig. 13. (a) Transmission of different glass-ceramics obtained from the $62.5 \mathrm{GeS}_{2}-12.5 \mathrm{Sb}_{2} \mathrm{~S}_{3}-$ 25CsCl-based glass powder for SPS treatment times of $2 \mathrm{~min}, 30 \mathrm{~min}, 60 \mathrm{~min}, 90 \mathrm{~min}$, and $120 \mathrm{~min}$ at $290^{\circ} \mathrm{C}$ under $100 \mathrm{MPa}$ (thickness $1 \mathrm{~mm}$ ) (b) Visual aspect of glass-ceramics samples for SPS treatment times of (a) $10 \mathrm{~min}$, (b) $30 \mathrm{~min}$, (c) $60 \mathrm{~min}$, (d) $90 \mathrm{~min}$, and (e) $120 \mathrm{~min}$ at $290^{\circ} \mathrm{C}$ under $100 \mathrm{MPa}$, (c) Observation of glass-ceramics under scanning electronic microscope for SPS treatment times of $2 \mathrm{~min}, 10 \mathrm{~min}, 30 \mathrm{~min}, 60 \mathrm{~min}, 90 \mathrm{~min}$, and $120 \mathrm{~min}$ at $290^{\circ} \mathrm{C}$ under $100 \mathrm{MPa}$.

\subsection{Mechanisms of sintering}

A specific study on the mechanisms of sintering of chalcogenide glassy powder by SPS has been investigated on the special composition $80 \mathrm{GeSe}_{2}-20 \mathrm{Ga}_{2} \mathrm{Se}_{3}$.

As previously mentioned, the Spark Plasma Sintering (SPS) technique is a non-conventional sintering technique based on the use of pulsed current. It is well known that the current distributions in the SPS die and through the sample is different in the case of a conductor and an insulator material (Anselmi-Tamburini et al., 2005). In the case of a non-electrically conducting sample such as alumina or the $80 \mathrm{GeSe}_{2}-20 \mathrm{Ga}_{2} \mathrm{Se}_{3}$ glassy powder in our case, no Joule heating is expected through the sample and the heating of the sample is mostly due to heating of the die. This is in contrast with the case of conducting materials such as metals sample, where Joule heating starts immediately through the sample. 
Due to the insulating property of the glass composition (Giridhar et al., 1990 \& Raspopova et al., 1980), it is thus believed that heating mostly occurs through heating of carbon die. This is confirmed by Perriere et al. who suggest that (Perriere et al., 2011)

$$
\frac{1}{I_{\text {applied }}}=\frac{1}{i_{\text {die }}}+\frac{1}{i_{\text {powder }}}
$$

considering an equivalent electrical outline of the SPS apparatus. Therefore,

$$
i_{\text {powder }}=I_{\text {applied }} \times \frac{1}{1+\frac{R_{\text {powder }}}{R_{\text {die }}}}
$$

With $i_{\text {powder }}$ and $i_{\text {die }}$ the respectively electrical current passing through the chalcogenide glass powder and the die, $\mathrm{I}_{\text {applied }}$ the macroscopic current intensity applied to the system,

$$
R_{\text {powder }}=\frac{\rho_{\text {powder } \times l_{\text {powder }}}}{S_{\text {powder }}} \quad \text { (5), } R_{\text {die }}=\frac{\rho_{\text {die } \times l_{\text {die }}}}{S_{\text {die }}}
$$

with $\rho_{\text {die }}$ and $\rho_{\text {powder }}$ the respectively electrical resistivity of the die and the powder, $1_{\text {die }}$ and $1_{\text {powder }}$ the length of the die and the powder crossed by the current, $S_{\text {die }}$ and $S_{\text {powder }}$ the respectively areas of the die or the powder crossed by the current.

Considering an electrical conductivity $\sigma_{\text {powder }}=1 \times 10^{-5} \mathrm{~S} . \mathrm{m}^{-1}$ at $390^{\circ} \mathrm{C}$ (Giridhar et al., 1990), i.e $\rho_{\text {powder }}=1 \times 10^{5} \Omega . \mathrm{m}$ and $\rho_{\text {die }}=20 \times 10^{-6} \Omega . \mathrm{m}, 1_{\text {die }}=30 \mathrm{~mm}, 1_{\text {powder }}=1.5 \mathrm{~mm}, \varnothing_{\text {die }}=25 \mathrm{~mm}$ and $\varnothing_{\text {powder }}=8 \mathrm{~mm}$, we end with $i_{\text {powder }} \rightarrow 0$. The macroscopic current is therefore mostly driven by the graphite die. In the case of the $80 \mathrm{GeSe}_{2}-20 \mathrm{Ga}_{2} \mathrm{Se}_{3}$ amorphous powder, the SPS experiment can thus be seen as a Hot Uniaxial Pressing (HUP) experiment with faster heating rate.

The sintering of glass occurs by viscous flow, to reduce surface energy of a porous compact, through neck growth and densification involving deformation of initial particles (Rahamn, 2008). Different mechanisms leading to the production of glass-ceramics have been hypothesized. The first one would be the densification of glassy powder through viscous sintering followed by subsequent devitrification of the matrix. The second mechanism would imply densification and concurrent gradual crystallization of the matrix through the growth of neck between glassy particles. For one given glass composition, the corresponding crystalline phase has a considerably higher viscosity than the amorphous phase, so the sintering of polycrystalline material is more difficult than the amorphous phase. This suggests that the first mechanism described above, i.e achieving full density prior to any significant crystallization should be favored. However, in the specific case of metallic glasses, it is reported that concurrent mechanisms are involved during SPS treatment (Perriere et al., 2011).

Sintering of powdered glasses based on a viscous flow mechanism has been intensively studied by Frenkel, Scherer or Kingery and Berg (Frenkel, 1945; Kingery, 1955 \& Scherer, 1977). Especially Murray et al. described the densification process of amorphous powder under load. The theoretical model based on viscous flow mechanism obeys the following relationship (Murray et al., 1954):

$$
d D / d t=3 P / 4 \eta(1-D) \quad \text { or } \quad \ln (1-D)=-3 P / 4 \eta t+\ln \left(1-D_{i}\right)
$$


Where $D$ is the relative density $\left(D=\rho / \rho_{s}, \rho\right.$ : the measured density and $\rho_{s}$, the theoretical density), Di the initial relative density, $\eta$ the viscosity and $t$, the time. The slope of the $\ln (1-$ D) versus time $t$ can be used to calculate the viscosity at one given temperature.

A formal sintering analysis, in order to help formulate hypotheses concerning the mechanism(s) controlling densification and devitrification has been performed. The influence of the dwell temperature $\left(250^{\circ} \mathrm{C}, 280^{\circ} \mathrm{C}, 310^{\circ} \mathrm{C}, 330^{\circ} \mathrm{C}, 350^{\circ} \mathrm{C}, 370^{\circ} \mathrm{C}\right.$ and $\left.390^{\circ} \mathrm{C}\right)$ as well as the dwell time (2, 15 and $60 \mathrm{~min})$ were studied while keeping the load constant (50MPa). These temperatures were chosen according to the sintering curve (Fig. 14) obtained from an SPS experiment (SPS parameters: $390^{\circ} \mathrm{C}, 50 \mathrm{MPa}, 2$ minutes dwell time) where the full densification of glass is achieved without crystallization $\left(\mathrm{D}_{\text {glass }}=4.39\right)$. The heating rate is $100^{\circ} \mathrm{C} / \mathrm{min}$ until $200^{\circ} \mathrm{C}$ and is then decreased to $30^{\circ} \mathrm{C} / \mathrm{min}$ until the set temperature, i.e $390^{\circ} \mathrm{C}$. The sintering of the glass is a two-step process. At $270^{\circ} \mathrm{C}$, the shrinkage starts intensively. Viscous flow between particles leads to the formation of a neck. The growth of the necks occurs until $350^{\circ} \mathrm{C}$ which corresponds to the $\mathrm{Tg}$ of the glass $\left(347^{\circ} \mathrm{C}\right)$. Then the mechanism of densification slows down and restarts around $360^{\circ} \mathrm{C}$ with lower amplitude. This second mechanism is believed to correspond to the closure of residual porosity measured from the Archimedean technique which is less than $10 \%$ at this stage.


Fig. 14. Shrinkage rate $(\mathrm{dz} / \mathrm{dt})$ and load applied as a function of temperature during SPS experiment.

Fig. 15 shows micrographs obtained on the fracture surface of powder compacts heat treated at different temperatures from $250^{\circ} \mathrm{C}$ to $390^{\circ} \mathrm{C}$ for 2 minutes dwell time (load of 50MPa). At $290^{\circ} \mathrm{C}$, far below the glass transition temperature $\mathrm{Tg}$, the particles begin to soften and fuse together but a lot of inter-granular porosity is still present $(27 \%)$. At $390^{\circ} \mathrm{C}$, particles are totally fused together and no porosity is observed.

The relative densities, $\mathrm{D}$, according to the dwell temperature and dwell time are reported in Figs. $16 \mathrm{a}$ and $16 \mathrm{~b}$. At $250^{\circ} \mathrm{C}$, the compactness is only $70 \%$. The residual porosity decreases gradually until $390^{\circ} \mathrm{C}$ where the full densification is obtained.

The influence of the dwell time at one given temperature was also studied. For all the dwell temperatures, the compactness regularly increases upon the increase in dwell time, for example from $90 \%\left(370^{\circ} \mathrm{C}, 2 \mathrm{~min}\right)$ to $96 \%\left(370^{\circ} \mathrm{C}, 30 \mathrm{~min}\right)$. 

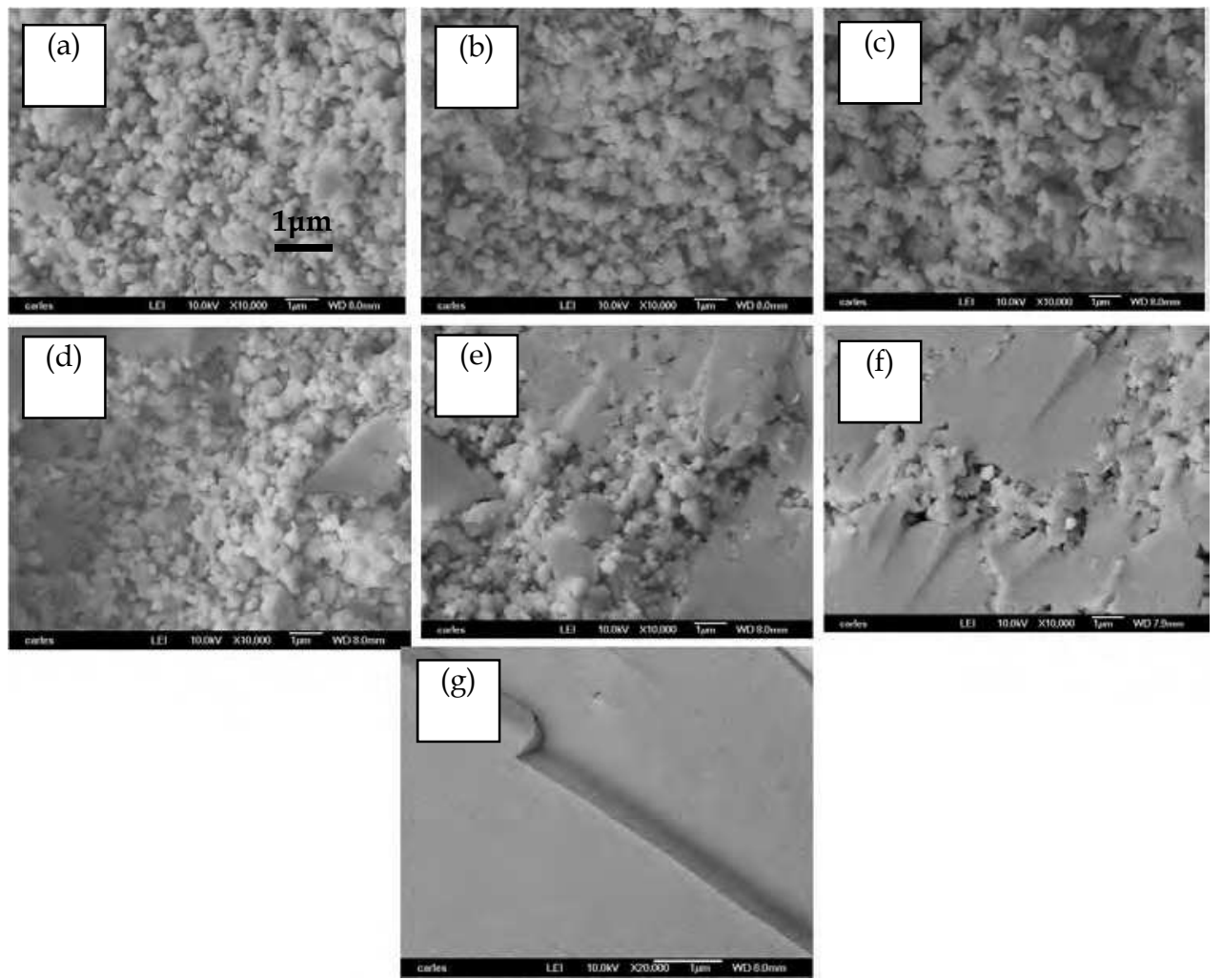

Fig. 15. FEG-SEM photographs of $80 \mathrm{GeSe}_{2}-20 \mathrm{Ga}_{2} \mathrm{Se}_{3} \mathrm{SPS}$ glass compacts sintered at different dwell temperatures (50MPa, 2 minutes dwell time), (a) $250^{\circ} \mathrm{C}$ (b) $280^{\circ} \mathrm{C}$ (c) $310^{\circ} \mathrm{C}$ (d) $330^{\circ} \mathrm{C}$ (e) $350^{\circ} \mathrm{C}$ (f) $370^{\circ} \mathrm{C}$ (g) $390^{\circ} \mathrm{C}$ (same scale for all the photographs).

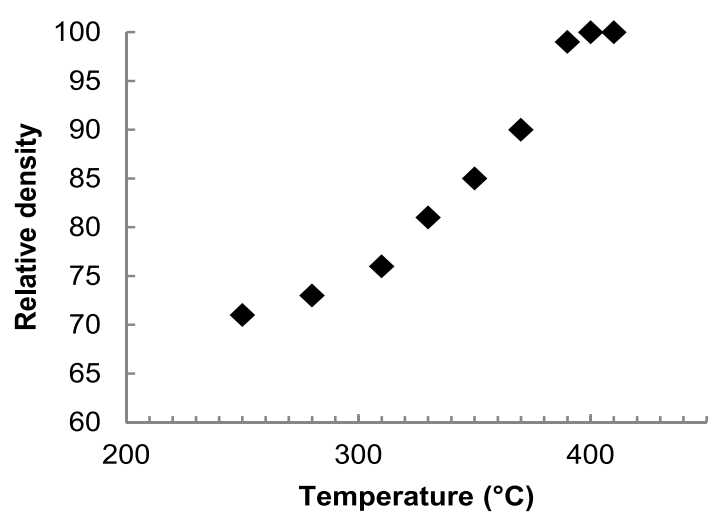

(a) 


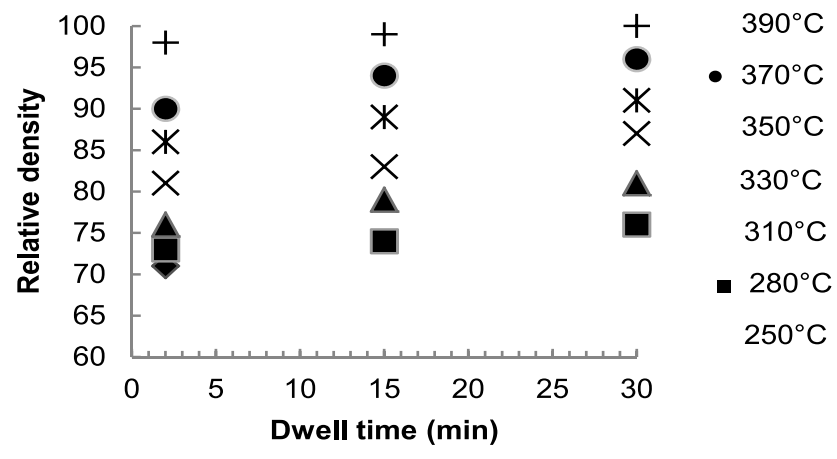

(b)

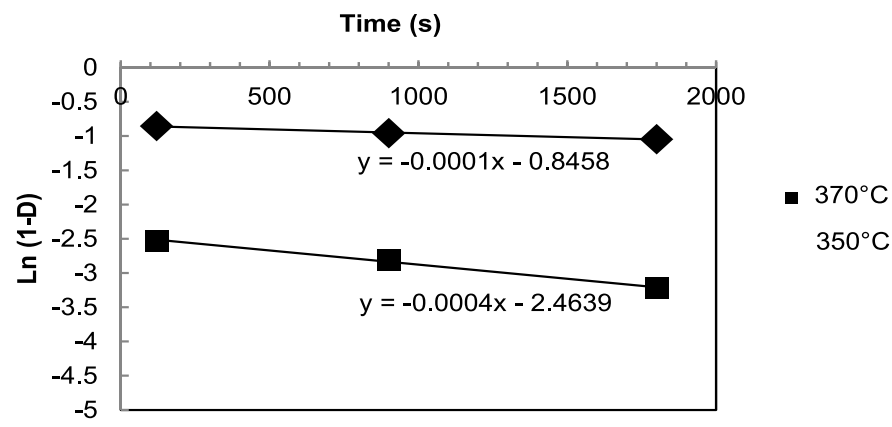

(c)

Fig. 16. (a) Influence of the dwell temperature on the relative density (50MPa, 2minutes dwell time), (b) Influence of the dwell time on the relative density for several dwell temperatures, (c) Plots of the ln (1-D) vs t curve for two dwell temperatures.

At $390^{\circ} \mathrm{C}$ for 2 minutes dwell time, the almost full densification of the glass is reached and the glass remains amorphous as shown by XRD patterns (Fig. 17). At this temperature only, the increase of dwell time induces partial devitrification of the glass as shown in Figs. 17 and 18. The crystals composition is $\mathrm{Ga}_{2} \mathrm{Se}_{3}$ (or $\mathrm{GaGe}_{4} \mathrm{Se}_{8}$ ) (Roze et al., 2008). Thus, there is clear evidence of densification mechanism prior to devitrification.

From eq. (7), we can deduce the viscosity for one given temperature (Fig. 16c). For temperatures close to the glass transition temperature, $\mathrm{Tg}$, or higher temperatures, calculations give $\eta\left(350^{\circ} \mathrm{C}\right) \sim 2 \times 10^{11}$ Pa.s and $\eta\left(370^{\circ} \mathrm{C}\right) \sim 9 \times 10^{10}$ Pa.s (Fig. 16c). Considering a Newtonian behavior in this range of temperature (Roze et al., 2011), the dependence of its viscosity as a function of temperature can be described by a simple Arrhenius equation:

$$
\eta=\eta_{0} e^{E_{\eta}} / R T
$$


where $\eta$ is the viscosity, $\eta_{0}$ the pre-exponential factor, $R$ the universal gas constant, $T$ the temperature and $E_{\eta}$ is the activation energy of viscous flow.

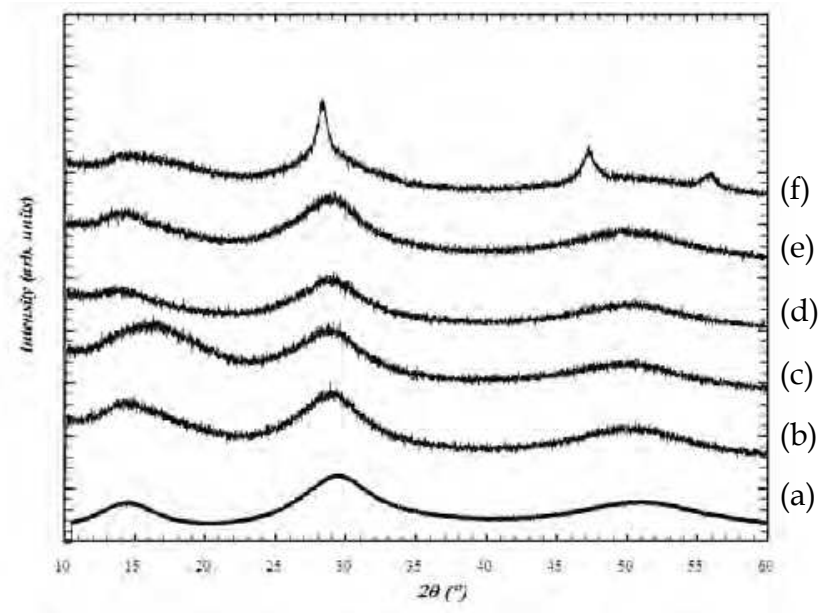

Fig. 17. XRD patterns of (a) $80 \mathrm{GeSe}_{2}-20 \mathrm{Ga}_{2} \mathrm{Se}_{3}$ initial powder, (b) SPS glass sample $\left(370^{\circ} \mathrm{C}\right.$, $\left.50 \mathrm{MPa}, 15^{\prime}\right)(\mathrm{c}) \mathrm{SPS}$ glass sample $\left(370^{\circ} \mathrm{C}, 50 \mathrm{MPa}, 30^{\prime}\right)(\mathrm{d})$ SPS glass sample $\left(390^{\circ} \mathrm{C}, 50 \mathrm{MPa}, 2^{\prime}\right)$ (e) SPS glass sample $\left(390^{\circ} \mathrm{C}, 50 \mathrm{MPa}, 15^{\prime}\right)$ (f) SPS glass sample $\left(390^{\circ} \mathrm{C}, 50 \mathrm{MPa}, 30^{\prime}\right)$.
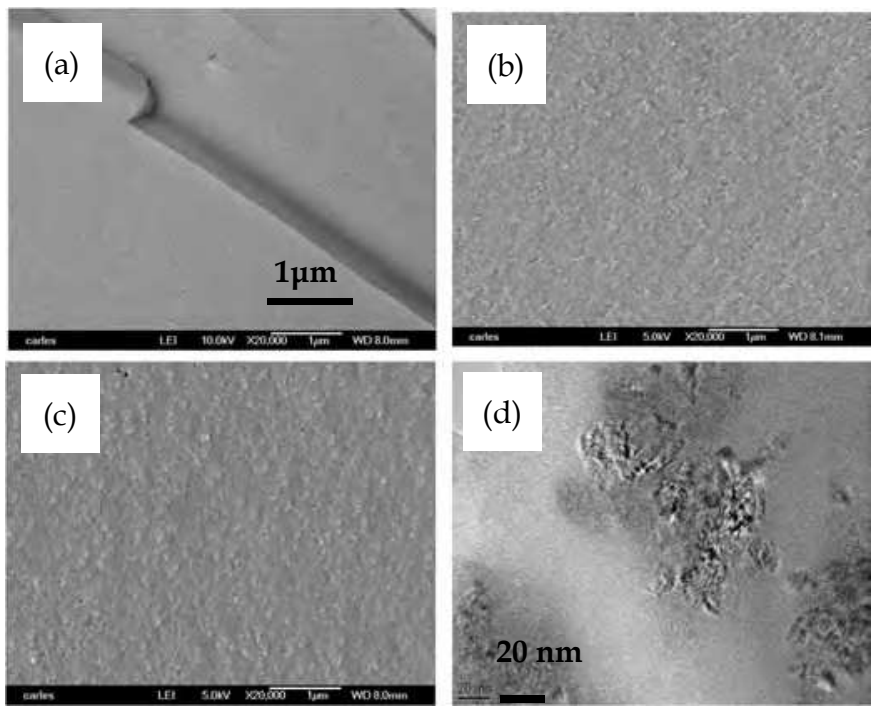

Fig. 18. FEG-SEM photographs of $80 \mathrm{GeSe}_{2}-20 \mathrm{Ga}_{2} \mathrm{Se}_{3} \mathrm{SPS}$ samples sintered at $390^{\circ} \mathrm{C}$ under $50 \mathrm{MPa}$ for different dwell times (a) 2 minutes, (b) 15 minutes, (c) 30 minutes, (d) TEM observation of glass-ceramic (c) obtained for SPS treatment time of $30 \mathrm{~min}\left(390^{\circ} \mathrm{C}, 50 \mathrm{MPa}\right)$ showing $\mathrm{Ga}_{2} \mathrm{Se}_{3}$ crystals. 
We can thus deduce the activation energy of viscosity between $\mathrm{Tg}$ and $\mathrm{Tc}_{1}$ from the curve $\mathrm{ln}$ $\eta=f(1 / T)$ which is found to be equal to $\sim 500 \pm 100 \mathrm{~kJ} . \mathrm{mol}^{-1}$ (Fig. 19). This value has been compared to literature on $80 \mathrm{GeSe}_{2}-20 \mathrm{Ga}_{2} \mathrm{Se}_{3}$ synthesized by the common melt-quenching technique instead of mechanical alloying (Roze et al., 2011). From the data viscosity, similar activation energy is found.

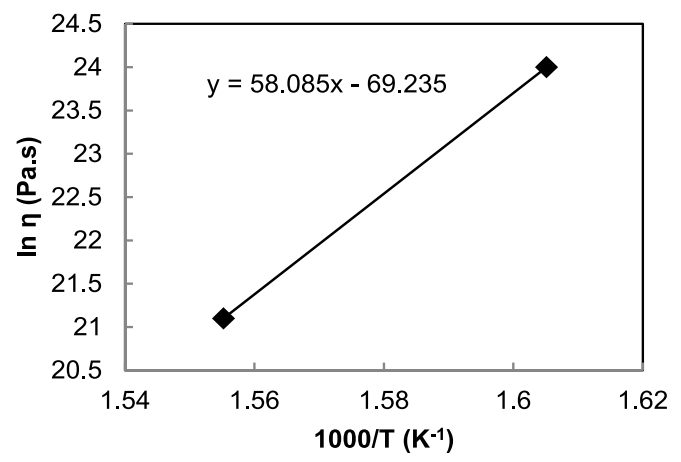

(a)

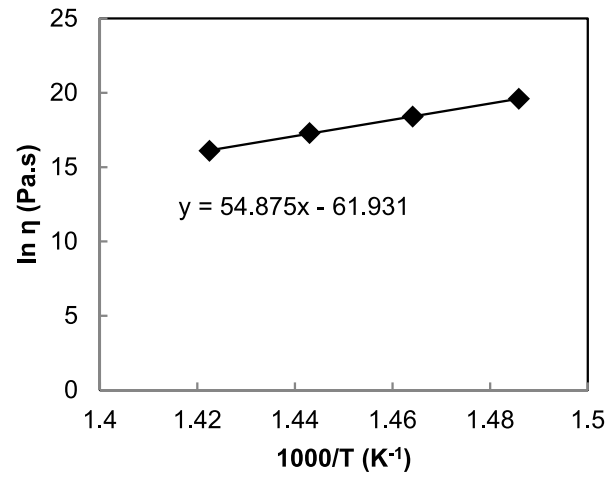

(b)

Fig. 19. Plots of the curve $\ln \eta=f(1 / T)$ in the case of our study (a) and in [63] (b).

\section{Conclusion}

This chapter provides an overview of a new technique to synthesize chalcogenide glasses and glass-ceramics. This technique combines either the synthesis of glass powder by mechanical milling or the grinding and sieving of pre-existing bulk obtained by the conventional melt-quenching technique and the PCES technique (or SPS). Many chalcogenide glasses presenting real potential applications were set aside since the common synthesis in sealed silica tubes under vacuum did not permit to produce samples big 
enough for applications without crystallization and inhomogeneity concerns. It offers the possibility to make glasses or glass-ceramics of desired shape and size with sintering slightly higher than the glass transition temperature in few minutes. Indeed, the fast heating rates of PCES allow getting amorphous bulks in few minutes and partial devitrification starts after tens of minutes. Thus, this new process would lead to lower manufacturing costs of new chalcogenide glasses and glass-ceramics which could be adapted to numerous setups such as thermal imaging, infrared laser sources and detectors, thermoelectric devices, etc. Ultimately, this new synthetic route will lead to larger scale production of infrared optics, broadening the target market to a more general public.

The mechanisms of sintering of one given chalcogenide glass composition that has an electrical insulating property have been investigated. Results show that heating of the glass powder occurs mainly through the heating of the die due to the electrical insulating property of the glassy powder. It is also shown that densification of the glass powder occurs prior to the devitrification of the glass. The model of Murray et al. has been successfully applied to our glass and allows the determination of viscosity and activation energy for viscosity between $\mathrm{Tg}$ and $\mathrm{Tc}$.

\section{References}

Aboulaich, A.; Bouchet, R.; Delaizir, G.; Seznec, V.; Tortet, L.; Rozier, P.; Morcrette, M.; Tarascon, J. M.; Viallet, V. \& Dollé, M. (2011). A New Approach to Develop Safe AllInorganic Monolithic Li-Ion Batteries. Advanced Energy Materials, Vol 2, pp. 179-183

Anselmi-Tamburini, U.; Gennari, S.; Garay, J. E. \& Munir, Z. A. (2005). Fundamental investigations on the spark plasma sintering/synthesis process: II. Modeling of current and temperature distributions. Materials Science and Engineering A, Vol 394, pp. 139-148

Avrami, M. (1939). Kinetics of phase change. I, General theory. Journal of Chemical Physics, Vol 7, pp. 1103-1112

Bernard-Granger, G; Benameur, N.; Guizard, C. \& Nygren, M. (2009). Influence of graphite contamination on the optical properties of transparent spinel obtained by spark plasma sintering. Scripta Materialia, Vol 60, pp. 164-167

Calvez, L.; Ma, H. L.; Lucas, J.; Zhang, X. H. (2007). Selenium-based glasses and glassceramics transmitting light from the visible to the far IR. Advanced Materials, Vol 19, pp. $129-132$

Cheng, J. (1982). Properties and structure of the infrared-transmitting arsenic-germanium selenium-tin glass-ceramic system. Huadong Huagong Xueyuan Xuebao, Vol 3, pp. 337-351

Choi, S. R.; Gyekenyesi, J. P. (2003). Results of mechanical testing for Pyroceram glassceramic. NASA/TM, (NASA/TM-2003-212487), pp. 1-84

Choi, P. P.; Kim, J. S.; Nguyen, O. T. H. ; Kwon, D. H. \& Kwon, Y. S. (2006). Al-La-Ni-Fe Amorphous Alloys and Amorphous-crystalline Composites Produced by Mechanical Alloying. Materials Science Forum, Vol 510-511, pp. 290-293

Choi, P.; Kim, J. S; Nguyen, O. T. H.; Kwon, D. H.; Kwon, Y. S. \& Kim, J. C. (2007). Al-La-NiFe bulk metallic glasses produced by mechanical alloying and spark-plasma sintering. Materials Science and Engineering: A, Vol 449-451, pp. 1119-1122 
Danto, S.; Ruff, Z.; Wang, Z.; Joannopoulos, J. D. \& Fink, Y. (2010). Ovonic memory switching in multimaterials fibers. Advanced Functional Materials, Vol 21, pp. 1095-1101

Delaizir, G.; Dollé, M.; Rozier, P. \& Zhang, X. H. (2010). Spark Plasma Sintering: An easy way to Make Infrared Transparent Glass-Ceramics. Journal of the American Ceramic Society, Vol 93, pp. 2495-2498

Delogu, F. \& Cocco, G. (2005). Numerical simulations of structural modifications at a Ni-Zr sliding interface. Physical Review B, Vol 72 pp. 014124

Eckert, J.; Seidel, M.; Schlorke, N.; Kubler, A. \& Schultz, L. (1997). Synthesis and Properties of Mechanically Alloyed and Nanocrystalline Materials. Materials Science Forum, Vol 235, pp. 23-28

Elliott, S.R. (1991). Chalcogenide glasses. Materials Science and technology, Vol 9, pp. 375

Frenkel, J. (1945). Viscous flow of crystalline bodies under the action of surface tension. Journal of Physics, Vol 9, pp. 385-391

Galy, J.; Dolle, M.; Hungria, T.; Rozier, P. \& Monchoux, J. P. (2008). A new way to make solid state chemistry: Spark plasma synthesis of copper or silver vanadium oxide bronzes. Solid State Sciences, Vol 10, pp. 976-981

Giridhar, A. \& Mahadevan, S. (1990). Chemical ordering in Ge-Ga-Se glasses. Journal of NonCrystalline Solids, Vol 126, pp. 161-169

Goncalves, A. P; Lopes, E. B.; Rouleau, O. \& Godart, C. (2010). Conducting glasses as new potential thermoelectric materials: the $\mathrm{Cu}-\mathrm{Ge}-\mathrm{Te}$ case. Journal of Materials Chemistry, Vol 20, pp. 1516-1521

Guillevic, E.; Zhang, X. H.; Pain, T.; Calvez, L.; Adam, J. L.; Lucas, J.; Guilloux-Viry, M.; Ollivier, S. \& Gadret, G. (2009). Optimization of chalcogenide glass in the As-Se-S system for automotive applications. Optical Materials, Vol 31, pp. 1688-1692

Gutzow, I.; Pascova, R.; Karamanov, A. \& Schmelzer, J. (1998). The kinetics of surface induced sinter crystallization and the formation of glass-ceramic materials. Journal of Materials Sciences, Vol 33, pp. 5265-5273

Hayashi, A.; Hama, S.; Morimoto, H.; Tatsumisago, M. \& Minami, T. (2001). Preparation of $\mathrm{Li}_{2} \mathrm{~S}_{-} \mathrm{P}_{2} \mathrm{~S}_{5}$ Amorphous Solid Electrolytes by Mechanical Milling. Journal of the American Ceramic Society, Vol 84, pp. 477-479

Hubert, M.; Delaizir, G.; Monnier, J.; Godart, C.; Ma, H. L.; Zhang, X. H. \& Calvez, L. (2011) submitted to Journal of Materials Chemistry

Hungria, T.; Galy, J. \& Castro, A. (2009). Spark Plasma Sintering as a Useful Technique to the Nanostructuration of Piezo-Ferroelectric Materials. Advanced Engineering Materials, Vol 11, pp. 615-631

Inoue, K., (1962) U.S. Patent No. 3241956

Inoue, K., (1966) U.S. Patent No. 3250892

Johnson, W. L. (1986). Thermodynamic and kinetic aspects of the crystal to glass transformation in metallic materials. Progress in Materials Science, Vol 30, pp. 81-134

Kingery, W. D. \& Berg, M. (1955). Study of the Initial Stages of Sintering Solids by Viscous Flow Evaporation-Condensation, and Self-Diffusion. Journal of Applied Physics, Vol 26, pp. 1205-1212

Kittel, C. (1998). Physique de l'état solide. Dunod, Paris

Kim, T. S.; Lee, J. K.; Kim, H. J. \& Bae, J. C. (2005). Consolidation of Cu47Ti34Zr11Ni8 bulk amorphous alloy powders. Materials Science and Engineering: A, Vol 402, pp. 228-233 
Klocek, P.; Roth, M. \& Rock, R. D. (1987). Chalcogenide glass optical fibers and image properties and applications. Optical Engineering, Vol 26, pp. 88-95

Li, Q.; Wang, G.; Song, X.; Fan, L.; Hu, W.; Xiao, F.; Yang, Q.; Ma, M.; Zhang, J. \& Liu, R. (2009). $\mathrm{Ti}_{50} \mathrm{Cu}_{23} \mathrm{Ni}_{20} \mathrm{Sn}_{7}$ bulk metallic glasses prepared by mechanical alloying and sparkplasma sintering. Journal of Materials Processing Technology, Vol 209, pp. 3285-3288

Li, Y. Y.; Yang, C.; Qu, S. G.; Li, X. Q. \& Chen, W. P. (2010). Nucleation and growth mechanism of crystalline phase for fabrication of ultrafine-grained $\mathrm{Ti}_{66} \mathrm{Nb}_{13} \mathrm{Cu}_{8} \mathrm{Ni}_{6.8} \mathrm{Al}_{6.2}$ composites by spark plasma sintering and crystallization of amorphous phase. Materials Science and Engineering: A, Vol 528, pp. 486-493

Lund, A. C. \& Schuh, C. A. (2004). Topological and chemical arrangement of binary alloys during severe deformation. Journal of Applied Physics, Vol 95, pp. 4815-4822

Ma, H. L.; Zhang, X. H. \& Lucas, J. (2003). Infrared transmitting chalcogenide glass ceramics. Journal of Non-Crystalline Solids, Vol 317, pp. 270-274

Machado, K. D ; De Lima, J. C. ; Campos, C. E. M ; Gasperini, A. A. M. ; De Souza, S. M. ; Maurmann, C. E; Grandi, T. A. \& Pizani, P. S. (2005). Reverse Monte Carlo simulations and Raman scattering of an amorphous $\mathrm{GeSe}_{4}$ alloy produced by mechanical alloying. Solid State Communications, Vol 133, pp. 411-416

Mayerhöfer, T. G; Shen, Z.; Leonova, E.; Edén, M.; Kriltz, A.; Popp, J. (2008). Consolidated silica glass from nanoparticles. Journal of Solid State Chemistry, Vol 181, pp. 2442-2447

Mc. Millan, P. W. (1979). Glass ceramics, Academic Press, second edition

Mecholsky, J. J.; Moynihan, C. T.; Macedo, P. B. \& Srinivasan, G. R. (1976). Microstructure and properties of an infra-red transmitting chalcogenide glass-ceramic. Journal of Materials Science, Vol 11, pp. 1952-1960

Murray, P.; Rodgers, E. P. \& Williams, A. E. (1954). Practical and theoretical aspects of the hot pressing of refractory oxides. Transactions and Journal of the British Ceramic Society, Vol 53, pp. 474-509

Nowak, S.; Perrière, L.; Dembinski, L.; Tusseau-Nenez, S. \& Champion, Y. (2011). Approach of the spark plasma sintering mechanism in $\mathrm{Zr}_{57} \mathrm{Cu}_{20} \mathrm{Al}_{10} \mathrm{Ni}_{8} \mathrm{Ti}_{5}$ metallic glass. Journal of Alloys and Compounds, Vol 509, pp. 1011-1019

Orru, R.; Licheri, R.; Mario Loccib, A.; Cincotti, A. \& Cao, G. (2009). Consolidation/synthesis of materials by electric current activated/assisted sintering. Materials Science and Engineering $R$, Vol 63, pp. 127-287

Patil, U.; Hong, S. J. \& Suryanarayana, C. (2005). An Unusual Phase Transformation during Mechanical Alloying of an Fe-based Bulk Metallic Glass Composition. Journal of Alloys and Compounds, Vol 389, pp. 121

Perriere, L.; Thai, M. T.; Tusseau-Nenez, S.; Bletry, M. \& Champion, Y. (2011). Spark Plasma Sintering of a Zr-Based Metallic Glass. Advanced Engineering Materials, Vol 13, pp. 581-586

Rahamn, M. N. (2008). Sintering of ceramic. CRC Press edited by Taylor and Francis group, pp 47

Raspopova, E. M.; Kolomiets, B. T.; Shilo, V. P. \& Smirnova, N. N. (1980). Electrical properties of Ga-Ge-Se chalcogenide glasses doped with REE. Physica Status Solidi A, Vol 59, pp. K235-K240

Riello, P.; Bucella, S.; Zamengo, L.; Anselmi-Tamburini, U.; Francini, R.; Pietrantoni, S. \& Munir, Z. A. (2006). Erbium-doped LAS glass ceramics prepared by spark plasma sintering (SPS). Journal of the European Ceramic Society, Vol 26, pp. 3301-3306 
Roze, M.; Calvez, L.; Ledemi, Y.; Ma, H. L.; Lucas, J. \& Zhang, X. H. (2008). Optical and thermo-mechanical properties of new Ge-Ga-Se-AgI glasses. Journal of Optoelectronics and Advanced Materials, Vol 10, pp. 141-144

Roze, M.; Calvez, L.; Hubert, M.; Toupin, P.; Bureau, B.; Boussard-Pledel, C. \& Zhang, X. H. (2011). Molded Glass-Ceramics for Infrared Applications. International Journal of Applied Glass Science, Vol 2, pp. 129-136

Saito, S. \& Sawaoka, A. (1973). Powder Metallurgy International, Vol 5, pp. 70-75

Scherer, G. W. (1977). Sintering of Low Density Glasses: II. Experimental Study. Journal of the American Ceramic Society, Vol 60, pp. 239-243

Schurack, F.; Borner, I.; Eckert, J. \& Schultz, L. (1999). Synthesis and Properties of Mechanically Alloyed and Ball Milled High Strength Amorphous or Quasicristalline Al-Alloys. Materials Science Forum, Vol 312-314, pp 49-54

Sekine, M.; Suzuki, Y.; Ueno, H.; Onodera, Y.; Usuki, T.; Nasu, T. \& Wei, S. (2007). Appearance of fast ionic conduction in AgI-doped chalcogenide glass powders prepared by mechanical milling. Journal of Non-Crystalline Solids, Vol 353, pp. 2069-2073

Shin, S.; Kim, T. S. \& Kang, S. K. (2010). The influence of spark plasma sintering temperature on the mechanical properties and corrosion resistance of $\mathrm{Zr}_{65} \mathrm{Al}_{10} \mathrm{Ni}_{10} \mathrm{Cu}_{15}$ metallic glass powder. Intermetallics, Vol 18, pp. 2005-2008

Shirakawa, Y.; Matsuda, T.; Tani, Y.; Shimosaka, A. \& Hidaka, J. (2001). Amorphization of Ge-GeSe mixtures in mechanical alloying process. Journal of Non-Crystalline Solids, Vol 293-295, pp. 764-768

Song, S. M.; Choi, S. Y. \& Lee, Y. K. (1997). Crystallization property effects in $\mathrm{Ge}_{30} \mathrm{Se}_{60} \mathrm{Te}_{10}$. Journal of Non-Crystalline Solids, Vol 217, pp. 79-82

Song, Z.; Kishimoto, S. \& Shinya, N. (2004). A Novel Pulse-Current-Assisted Sintering Method for Fabrication of Metallic Cellular Structures. Advanced Engineering Materials, Vol 6, pp. 211-214

Strnad, Z. (1986). Glass-Ceramic Materials. Publishers of Technical Literature, Prague, 185

Trevey, J.; Jang, J. S.; Jung, Y. S.; Stoldt, C. R. \& Lee, S. H. (2009). Glass-ceramic Li $2 \mathrm{~S}_{-} \mathrm{P}_{2} \mathrm{~S}_{5}$ electrolytes prepared by a single step ball billing process and their application for all-solid-state lithium-ion batteries. Electrochemistry Communications, Vol 11, pp. 1830-1833

Troles, J.; Coulombier, Q. ; Canat, G. ; Duhant, M. ; Renard, W. ; Toupin, P. ; Calvez, L. ; Renversez, G. ; Smektala, F. ; El Amraoui, M. ; Adam, J. L. ; Chartier, T. ; Mechin, D. \& Brilland, L. (2010). Low loss microstructured chalcogenide fibers for large non linear effects at $1995 \mathrm{~nm}$. Optics Express, Vol 18, pp. 26647-26654

Wilhelm, A.; Boussard-Pledel, C.; Coulombier, Q.; Lucas, J.; Bureau, B. \& Lucas, P. (2007). Development of Far-Infrared-Transmitting Te Based Glasses Suitable for Carbon Dioxide Detection and Space Optics. Advanced Materials, Vol 19, pp. 3796-3800

Yan, X.; Song, X.; Lu, N.; Li, E. \& Zhang, J. (2008). A novel route for preparing binary Sm-Co bulk amorphous alloys. Materials Letters, Vol 62, pp. 2862-2864

Zhang, X. H.; Guimond, Y.\& Bellec, Y. (2003). Production of complex chalcogenide glass optics by molding for thermal imaging. Journal of Non-Crystalline Solids, Vol 326327, pp. 519-523

Zhang, X. H.; Ma, H. L. \& Lucas, J. (2004). A new class of infrared transmitting glass-ceramic based on controlled nucleation and growth of alkali halide in a sulphide based glass matrix. Journal of Non-Crystalline Solids, Vol 337, pp. 130-135 


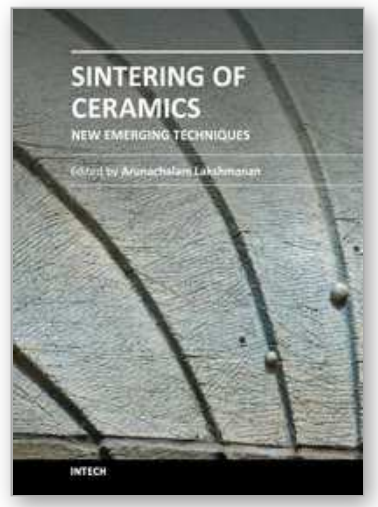

\author{
Sintering of Ceramics - New Emerging Techniques \\ Edited by Dr. Arunachalam Lakshmanan
}

ISBN 978-953-51-0017-1

Hard cover, 610 pages

Publisher InTech

Published online 02, March, 2012

Published in print edition March, 2012

The chapters covered in this book include emerging new techniques on sintering. Major experts in this field contributed to this book and presented their research. Topics covered in this publication include Spark plasma sintering, Magnetic Pulsed compaction, Low Temperature Co-fired Ceramic technology for the preparation of 3-dimesinal circuits, Microwave sintering of thermistor ceramics, Synthesis of Bio-compatible ceramics, Sintering of Rare Earth Doped Bismuth Titanate Ceramics prepared by Soft Combustion, nanostructured ceramics, alternative solid-state reaction routes yielding densified bulk ceramics and nanopowders, Sintering of intermetallic superconductors such as MgB2, impurity doping in luminescence phosphors synthesized using soft techniques, etc. Other advanced sintering techniques such as radiation thermal sintering for the manufacture of thin film solid oxide fuel cells are also described.

\title{
How to reference
}

In order to correctly reference this scholarly work, feel free to copy and paste the following:

Gaelle Delaizir and Laurent Calvez (2012). A Novel Approach to Develop Chalcogenide Glasses and GlassCeramics by Pulsed Current Electrical Sintering (PCES), Sintering of Ceramics - New Emerging Techniques, Dr. Arunachalam Lakshmanan (Ed.), ISBN: 978-953-51-0017-1, InTech, Available from: http://www.intechopen.com/books/sintering-of-ceramics-new-emerging-techniques/preparation-ofchalcogenide-glasses-and-glass-ceramics-by-pulsed-electric-current-sintering-pecs-

\section{INTECH}

open science | open minds

\author{
InTech Europe \\ University Campus STeP Ri \\ Slavka Krautzeka 83/A \\ 51000 Rijeka, Croatia \\ Phone: +385 (51) 770447 \\ Fax: +385 (51) 686166 \\ www.intechopen.com
}

\author{
InTech China \\ Unit 405, Office Block, Hotel Equatorial Shanghai \\ No.65, Yan An Road (West), Shanghai, 200040, China \\ 中国上海市延安西路65号上海国际贵都大饭店办公楼 405 单元 \\ Phone: +86-21-62489820 \\ Fax: $+86-21-62489821$
}


(C) 2012 The Author(s). Licensee IntechOpen. This is an open access article distributed under the terms of the Creative Commons Attribution 3.0 License, which permits unrestricted use, distribution, and reproduction in any medium, provided the original work is properly cited. 